\title{
Beiträge zur Entwicklungsgeschichte von Sciaphila spec. und von Epirrhizanthes elongata $\mathrm{BI}$.
}

\author{
Von Hans Wirz.
}

(Laboratorium für allgemeine Botanik ụd Pflanzenphysiologie der Universität Zürich.)

(Mit Tafel IV und 22 Abbildungen im Text.)

\section{Einleitung.}

Die beiden Pflanzen, deren Embryologie in vorliegender Arbeit geschildert werden soll, gehören zur biologischen Gruppe der Verwesungspflanzen, die bekanntlich in ihrer Lebensweise und dementsprechend auch in ihrem Bau und ihrer Entwicklung oft recht interessante und eigentümliche Verhältnisse zeigen. Das Untersuchungsmaterial wurde von Professor Dr. Ernst während seines Aufenthaltes auf Java (1905/06) gesammelt und mir in gütiger Weise zur Verfügung gestellt. Zur Fixierung der Objekte waren Alkohol, Sublimatalkohol, das Dreisäurengemisch nach Flemming und die Pfeiffer'sche Lösung verwandt worden. Am günstigsten für die Untersuchung erwies sich das Material, das mit Chromessigsäure nach Pfeiffer behandelt worden war. Die Schwärzung der Gewebe, die sich bei der Fixierung mit Chrom-OsmiumEssigsäure eingestellt hatte, ließ sich bei Einwirkung von Wasserstoffsuperoxyd so weit heben, daß sie die Färbung nicht beeinträchtigte. Am häufigsten verwendete ich zur Färbung der Schnitte das Hämatoxylinverfahren nach Haidenhein, in zweiter Linie auch Delafieldsches Hämatoxylin. In beiden Fällen ließ ich eine Nachfärbung mit Magdalarot folgen, das von den Kernkörperchen intensiv gespeichert wird und dem Plasma einen rötlichen Ton gibt. Auch die Flemmingsche Dreifachfärbung wurde häufig angewendet und ergab teilweise gute Resultate.

\section{Beiträge zur Entwicklungsgeschichte von Epirrhizanthes elongata B1.}

Epirrhizanthes elongata Bl., deren Blüten- und Samenentwicklung in den folgenden Abschnitten besprochen werden soll, gehört zur Familie der Polygalaceen. In Engler und Prantl: „Die natürlichen Pflanzenfamilien"1) ist die Gattung Epirrhizanthes unter dem Namen Salomonia aufgeführt. Außer Epirrhizanthes elongata Bl. ist auch

1) Engler u. Prantl, „Die natürlichen Pflanzenfamilien“, III. Teil, Abt. 4, pag. 342, Leipzig 1897.

Flora, Bd. 101. 
Epirrhizanthes cylindrica Bl. untersucht worden. Da Indessen die beiden Arten in ihrer Entwicklung fast vollständig übereinstimmen, ist eine gesonderte Betrachtung nicht nötig. Ich werde mich daher im folgenden in der Hauptsache auf eine Darstellung der.Verhältnisse bei Epirrhizanthes elongata Bl. beschränken und auf etwaige Abweichungen bei Epirrhizanthes cylindrica, von der mir auch weniger Material zur Verfügung stand, hinweisen.

\section{Morphologie der Bliite.}

Penzig ${ }^{1}$ ) gibt in seiner Arbeit: „Beiträge zur Kenntnis der Gattung Epirrhizanthes Bl." eine eingehende Schilderung der äußeren Morphologie der Blüten von Epirrhizanthes cylindrica und elongata. Ich kann mich daher in diesem Kapitel auf wenige Angaben, die zum Verständnis der folgenden Ausführungen notwendig erscheinen, beschränken.

Wie bei den meisten Polygalaceen stehen auch bei der Gattung Epirrhizanthes, die nach Penzig (1. c. pag. 146) nur die beiden oben angeführten Arten umfaßt, die Blüten in endständigen, dichten Ähren. Die einzelnen Blüten sind zwitterig und entstehen in akropetaler Reihenfolge in den Achseln von länglichen, zugespitzten, konkaven Bracteen. Ihre Stiele sind sehr kurz. Die Kelchblätter treten in der für die Polygalaceen charakteristischen Zahl von fünf auf und sind am Grunde etwas miteinander verwachsen. Im innern Perianthkreis ist die Zahl der Glieder reduziert. Es treten nur drei Blumenblätter auf, von denen das vorderste, die Carina, eine besondere Ausbildung zeigt und kahnförmig ausgehöhlt ist. Die fünf Staubblätter (bei anderen Polygalaceen treten gewöhnlich ihrer acht auf) sind mit ihren Filamenten zu einem Staubfadenbündel, der sog. Staminalröhre, verwachsen. Die Mitte der Blüte wird von dem zweikarpelligen, von den Seiten her schwach zusammengedrückten Fruchtknoten eingenommen. Er trägt einen langen Griffel mit ungeteilter, papillenbedeckter Narbe. Jeder Fruchtknoten enthält zwei Samenanlagen in schwach anatroper Lage.

\section{Entwicklung der Blüte.}

Auf einem Querschnitt durch den obersten Teil des Blütenstandes erscheint die Ährenspindel noch drehrund. Um diese als Zentrum sind die Bracteen sehr regelmäßig in neun Reihen angeordnet (Text-

1) Penzig, O., „Beiträge zur Kenntnis der Gattung Epirrhizanthes Bl.“ Ann. du jard. bot. de Buitenzorg, 1901, Vol. XVII, pag. 158-160. 
figur 1 a). Sie stellen sich im Querschnitt als wenigschichtige, leicht gebogene Gewebestreifen dar. Im Wachstum eilen sie ihren Achselknospen, den zukünftigen Blüten um ein Bedeutendes voraus und die obersten bilden einen, den Vegetationskegel des Blütenstandes überragenden Schopf. Wenig unterhalb des wachsenden Scheitels tritt in der Spindelachse eine Differenzierung in ihrem Gewebe auf. Es differenziert sich in einen zentralen Zylinder aus größeren, wenig plasmareichen Zellen und einen peripheren Mantel aus Zellen mit dichtem, plasmatischem Inhalt. Aus diesem Gewebering, der wohl aus Periblem und Dermatogen sich aufbauen mag, sehen wir, je mehr wir uns der Basis des Blütenstandes nähern, die Blüten sich entwickeln. Ihre ersten Anlagen erscheinen als wulstige Protuberanzen, die, je weiter der Querschnitt vom Vegetationspunkt entfernt liegt, um so deutlicher hervortreten. In den oberen Teilen der
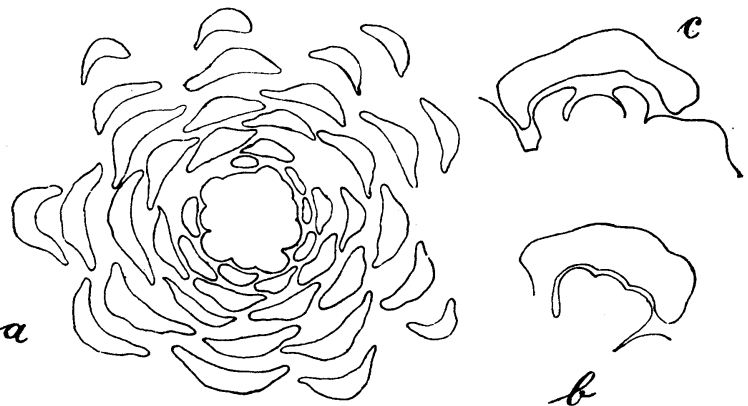

Fig. 1. Epirrhizanthes elongata Bl. a Querschnitt durch den Blütenstand unterhalb des Vegetationskegels. Die jüngsten Anlagen der Blüten erscheinen als Ausbuchtungen der Spindelachse. Bracteenquerschnitte in radialen Reihen. Vergr. 40/1. b Längsschnitt durch eine Blütenanlage. Die Kelchblätter beginnen sich zu bilden. Vergr. 70/1. c Die Kelchblätter überwölben die Blüte. Vergr. 70/1.

Ähre lassen sich, ent-

sprechend den neun radialen Reihen von Bracteen, ebensoviele Blütenanlagen auf einem Querschnitt nachweisen. Dieses Verhältnis verwischt sich später infolge der Streckung der Ährenspindel. Die wulstförmigen Gewebehöcker, die den zukünftigen Blüten entsprechen, heben sich durch ihre intensive Tinktion, bedingt durch den reichen Plasmagehalt, vom übrigen Gewebe deutlich ab. An ihnen entstehen im Verlaufe der Entwicklung, in Form papillenförmiger Ausstülpungen, zunächst die Kelchblätter, die sich rasch verlängern und über den primären Gewebehöcker hinüberwölben (Textfigur $1 b$ u. c). Ihnen folgen in der Anlage die Petalen und bald auch die Staubblätter. Das Gynäceum erscheint zuletzt und entwickelt sich am langsamsten. Es zeigt noch keinerlei morphologische oder anatomische Differenzierung, während man an den Staubblättern schon deutlich die Antheren erkennen kann. Die Anlage und Entwicklung der Blütenglieder erfolgt somit in akropetaler Reihenfolge. 


\section{Entwicklung und Bau der Antheren und der Pollenkörner.}

Wie schon erwähnt, werden die Staubblätter in Fünfzahl angelegt und eilen den Karpellen in der Entwicklung bedeutend voraus. Textfigur $2 a$ zeigt einen Querschnitt durch die junge Blüte von Epirrhizanthes elongata. Die Antheren sind in einem nicht ganz geschlossenen Kreise um den rundlichen Gewebehöcker, der die erste Anlage des Gynäceums darstellt, angeordnet und um diese Zeit von den eben gebildeten Petalen kaum zu unterscheiden. In ihrem Gewebe ist noch keine Differenzierung eingetreten. Als erster Schritt zu einer solchen macht sich in der Folge die Abhebung einer distinkten Lage von Epi-

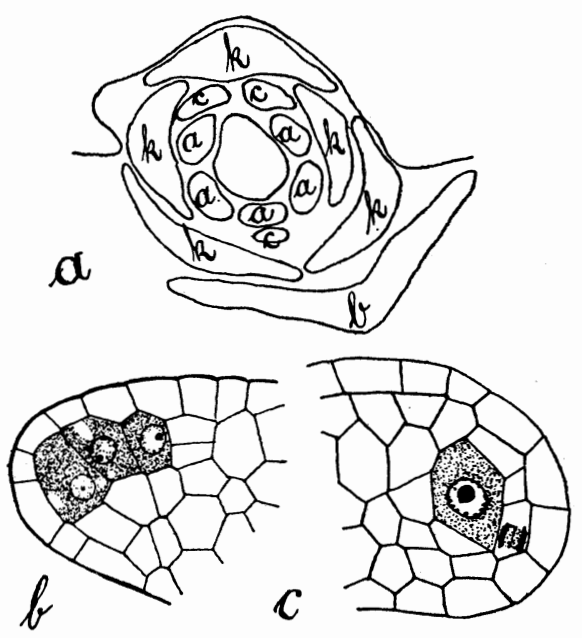

Fig. 2. Epirrhizanthes elongata. a Querschnitt durch eine junge Blüte. Vergr. 70/1. $b$ Querschnitt durch eine Antherenhälfte nach Bildung der Pollenmutterzellen. Vergr. 570/1. c Querschnitt durch eine Antherenhälfte. Pollenmutterzelle. Kernteilung in einer subepidermalen Zelle. Vergr. 570/1.

$k=$ Kelchblätter, $\quad a=$ Staubblätter,

$c=$ Kronblätter, $\quad b=$ Bractee. dermiszellen bemerkbar. Die Antheren zeigen schon jetzt die länglichrunde Gestalt, die sie während ihrer ganzen Entwicklung beibehalten. Die Entstehung und der innere Ausbau der Pollensäcke vollziehen sich in der für die meisten Dikotyledonen typischen Weise. Subepidermal treten Zellen im Gewebe der Antheren auf, die sich durch ihr bedeutenderes Volumen, durch die Größe ihres Kernes und den dichten Plasmagehalt von ihren Nachbarzellen unterscheiden (Textfigur $2 b$ ). Es sind die Urmutterzellen der Pollenkörner. Jede derselben gliedert durch eine tangentiale Teilung eine neue subepidermale Zelle ab und wird dann direkt, ohne weitere Teilung, zur Pollenmutterzelle. Die Zahl der letzteren ist demgemäß im Innern des Pollensackes der Antheren von Epirrhizanthes eine geringe. Ich traf nie mehr als drei oder vier in einem Pollensack, und da die Anthere nur zwei Loculi aufweist, kann sie im reifen Zustande höchstens 32 Pollenkörner enthalten. Durch perikline Teilungen der subepidermalen Zellage kommt es zur Ausbildung der vierschichtigen Antherenwandung. Bei der ersten Teilung 
entstehen die Tapetenschicht, die die Pollenmutterzellen unmittelbar umschließt, und eine äußere Zellage. Diese letztere erzeugt durch erneute perikline Teilung die subepidermale „fibröse Schicht“" und die nach innen auf die eben genannte Zellage folgende „zu verdrängende Schicht". Textfigur $3 c$ zeigt die der ersten periklinen Teilung einer subepidermalen Zelle vorausgehende Kernteilung.

Während in der angegebenen Weise die Ausbildung der Antherenwandung vor sich geht, zeigen auch die Pollenmutterzellen ein intensives Wachstum. Auf den Schnitten erscheinen sie unregelmäßig vierbis sechseckig, meist in einer Richtung etwas stärker gestreckt. Ihr Inhalt ist nicht dichter als derjenige der Nachbarzellen, die während der Größenzunahme der Pollenmutterzellen lebhafte Teilungen zeigen. Der Kern der Pollenmutterzellen übertrifft dagegen an Größe diejenigen der vegetativen Zellen um ein Bedeutendes. Die chromatische Substanz ist in Gestalt intensiv sich färbender Körnchen peripher der Kernwandung angelagert. Das in Einzahl vorhandene Kernkörperchen ist innerhalb eines hellen Hofes meist etwas exzentrisch gelagert. In seinem Inneren treten gewöhnlich Vakuolen auf, die bei Epirrhizanthes cylindrica eine ansehnliche Größe erreichen. Auch das Plasma der wachsenden Pollenkörner zeigt oft feinwabige bis deutlich vakuolige Struktur. Die Vakuolen sind dabei manchmal in einem Kreis um den Kern angeordnet und zeigen wiederum bei Epirrhizanthes cylindrica ein bedeutenderes Volumen.

Von den peripher gelagerten Chromatinkörnchen beginnen mit der Zeit zarte Lininfäden sich auszuspinnen gegen das Kernkörperchen zu, das sich entsprechend dem Wachstum des Kernes vergrößert. Der helle Hof um den Nukleolus wird enger und schließlich von einem feinmaschigen Netz achromatischer Substanz erfüllt. Während das Lininnetz den Kernraum durchspinnt, ist die chromatische Substanz anfangs noch zum großen Teil an der Kernwand gelagert. Später tritt sie auf das Kernnetz über und findet sich alsdann hauptsächlich in den Ecken der Maschen, den Kreuzungspunkten der Lininfäden, in Gestalt dichter Körnchen (Taf. IV, Fig. 1). Der Kern hat um diese Zeit seine größte Ausdehnung erreicht und nimmt etwa ein Drittel des Zellumens ein.

Den Vorgang der Synapsis konnte ich bei Epirrhizanthes sehr oft in allen seinen Phasen innerhalb der Pollenmutterzellen beobachten. Das Fadennetz löst sich zunächst von der Kernwand los und beginnt sich zu kontrahieren. Zuweilen sieht man das kontrahierte Kernnetz in einem kranzförmigen Ringe um das im Zentrum des Kernraumes liegende Kernkörperchen angeordnet. Einzelne Fäden des Kerngerüstes 
scheinen mit der Kernmembran fester verbunden $\mathrm{zu}$ sein. Sie haften ihr noch an, wenn sich der übrige Teil des Kernnetzes einseitig an einer Stelle der Kernwand anzulegen beginnt. Das Chromatinnetz zieht sich zu einem immer dichter werdenden Knäuel zusammen, der, wenn die Synapsis ihren höchsten Grad erreicht hat, seine feinere Struktur nicht mehr erkennen läßt. Aus dem halbmondförmigen Knäuel wird der Nukleolus ausgestoßen (Taf. IV, Fig. 2), liegt demselben jedoch stets dicht an. Während der Synapsis treten gewöhnlich neben dem einen großen noch mehrere kleine Kernkörperchen auf. Die Pollenmutterzellen sind zu dieser Zeit in der Regel noch nicht aus dem gegenseitigen Verbande gelöst. Im gleichen Pollensack, in der nämlichen Anthere finden sich die Pollenmutterzellen stets im selben Stadium der Entwicklung.

Verdoppelung und Segmentierung des Kernfadens konnte ich nicht beobachten.

Nach Beendigung des Synapsisstadiums ihrer Kerne weichen die Pollenmutterzellen auseinander und runden sich ab. Der Kern, der vorher meist eine exzentrische Lage gezeigt hatte, rückt in die Mitte der Zelle.

Sehr oft fanden sich in meinen Präparaten die beiden Teilungen, die zur Entstehung der Pollenkörner führen. Die Chromatinsubstanz war auf den ersten postsynaptischen Stadien, die zur Beobachtung gelangten, in Gestalt intensiv sich färbender Körperchen, die in Gruppen, wie es schien, oft $\mathrm{zu}$ vieren beisammen lagen, über den ganzen Kernraum verteilt. Da die Zahl dieser Gruppen oder Zentren chromatischer Substanz, die durch zarte Fäden miteinander verbunden sind, offenbar eine konstante ist, so ist nicht daran zu zweifeln, daß sie den Chromosomen identisch sind oder wenigstens Vorstufen derselben bilden. Die Zahl dieser Chromatingruppen schwankte nach meinen Zählungen zwischen 20 und 24, doch kann mit aller Wahrscheinlichkeit angenommen werden, daß 24 ihre wirkliche Zahl ist (Taf. IV, Fig. 3).

Gleich nach dem Auseinanderweichen und Abrunden der Pollenmutterzellen zeigt sich in ihrem Plasma eine eigentümliche Verdichtung. Sie beginnt an der Peripherie zunächst in einer schmalen Zone und rückt allmählich gegen innen vor. Auf dem Querschnitt erscheint die Verdichtung als anfangs schmaler, dann immer breiter werdender Ring (Taf. IV, Fig. 3). Bis zum Kern schreitet indessen die Verdichtung nicht vor. Um ihn bleibt stets eine Zone helleren Plasmas von körniger Natur erhalten. Der Plasmaring bleibt auch während der ersten Kernteilung, wenn die Kernwand sich auflöst, erhalten (Taf. IV, Fig. 4). 
Über seine Bedeutung vermag ich nichts auszusagen. Eine besondere faserige Struktur konnte ich an ihm nicht wahrnehmen, doch handelt es sich jedenfalls auch nicht um eine bloße Kontraktionserscheinung infolge der Präparation. Das regelmäßige Auftreten dieses Ringes nach der Abrundung der Pollenmutterzellen und der Teilung ihres Kernes vorausgehend, sein konstantes Fehlen noch während der Synapsis läßt eine solche Erklärung kaum zu.

Nach der Bildung der ersten beiden Tochterkerne scheint die Plasmaverdichtung für eine Zeitlang zu verschwinden, um bei der zweiten Teilung, die zur Entstehung der Enkelkerne führt, wieder aufzutreten (Taf. IV, Fig. 5).

Vor der ersten Teilung streckt sich die Pollenmutterzelle nach einer Richtung etwas und nimmt dadurch eine ovale Form an. In dem von dem besprochenen, dichten Plasmaringe umschlossenen, plasmaärmeren, hellen Hofe erscheint die verhältnismäßig lange Kernspindel, die mit ihren beiden Polen den peripheren Plasmaring berührt. Die äquatoriale Kernplatte und das Auseinanderweichen der Chromosomen konnte öfters beobachtet werden. Die letzteren sind sehr klein und stäbchenförmig.

Nachdem der Kern der Pollenmutterzellen sich in die vier Tochterkerne geteilt hat, erfolgt auch der Zerfall des Plasmas in vier tetraedrisch oder quadrantenförmig angeordnete Plasmapartien, die sich bald mit einer Membran umgeben (Taf. IV, Fig. 6 u. 7). Von einer Plasmaverdichtung, entsprechend jener an der Peripherie der Pollenmutterzellen, ist nichts mehr wahrzunehmen, hingegen sind die vier einer Pollenmutterzelle entstammenden Pollenkörner unmittelbar nach ihrer Bildung von einer gelblichen, lichtbrechenden Hülle umgeben, die der ursprünglichen Wand der Pollenmutterzelle oder Plasmaresten ihren Ursprung verdanken mag. Die sich abrundenden und an Größe rasch zunehmenden Pollenkörner sind nach Penzig (l. c. pag. 159) im ausgewachsenen Zustande: „verhältnismäßig groß, elliptisch-tonnenförmig mit etwa 14-15 Längsbanden und einem deutlichen Querreifen in der Mitte". An der gleichen Stelle gibt Penzig auch die Maße für die Pollenkörner von Epirrhizanthes cylindrica (l. c. pag. 159). Er fand ihre Länge $\mathrm{zu} 48-51 \mu$, ihre Breite $\mathrm{zu} 30-32 \mu$. Mit diesen Angaben stimmen meine eigenen Messungen genau überein. In einigen Fällen fand ich für die Pollenkörner Längen bis zu $54 \mu$.

Hingegen fand ich für die Pollenkörner von Epirrhizanthes elongata andere Werte als Penzig. Er bestimmte ihre Länge zu 33 bis $35 \mu$, ihre Breite zu 27-28 $\mu$; während nach meinen Messungen 
die Pollenkörner von Epirrhizanthes elongata, sowohl was ihre Länge als auch was ihre Dicke anbetrifft, denjenigen von Epirrhizanthes cylindrica nichts nachstanden, sondern die gleichen Maßverhältnisse zeigten. Ich bestimmte sodann auch die Größen der Pollenkörner für die erstere Art auf verschiedenen Entwicklungsstadien. Kurz nach der Tetradenteilung betrug ihre Länge ca. 19, ihre Breite ca. $14 \mu$. Für die einkernigen Pollenkörner, zur Zeit wo noch die Tapetenschicht der Pollensäcke vorhanden war, fand ich den Längsdurchmesser zu 26, den Breitendurchmesser zu $19 \mu$ und ein Pollenkorn, bei dem eben der Schlauch den Keimporus durchsetzte, zeigte eine Länge von 50, eine Dicke von $35 \mu$.

Die Längsstreifen, die man an der Wandung der Pollenkörner wahrnimmt, entsprechen, wie man an Querschnitten leicht feststellen kann, Fältelungen der Membran.

Im Bereich des äquatorialen Querreifens ist die Exine verdünnt. Hier liegen auch die Austrittsstellen für den Pollenschlauch. Ihre Zahl kommt derjenigen der Längsriefen gleich.

Unmittelbar nach der Tetradenteilung ist in den einzelnen Kernen die chromatische Substanz in Gestalt von Körnchen über den ganzen Kernraum verteilt. Das in Einzahl vorhandene Kernkörperchen zeigt in seinem Innern kleine Vakuolen. Wenn das Pollenkorn nach Ausbildung von Exine und Intine seine definitive, tonnenförmige Gestalt bekommen hat, trifft man den Kern regelmäßig auf der Höhe des äquatorialen Querreifens. Er hat mit der Größenzunahme seiner Zelle Schritt gehalten; dagegen erscheint er jetzt heller, ein Zeichen, daß sich die chromatische Substanz nicht in gleichem Maße vermehrt hat. Die letztere hat eine periphere Lagerung angenommen und von den wandständigen Chromatinkörnchen spinnt sich auch hier wieder ein feines Netz über den ganzen Kernraum aus. Unterdessen wandert der Kern an den einen Pol des Kornes, wo alsdann seine Teilung stattfindet. Die Kernspindel steht dabei etwas schief zur Längsachse des Pollenkornes (Taf. IV, Fig. 8), wie ich in mehreren Fällen beobachten konnte. Durch diese Teilung entstehen die beiden für die Angiospermen charakteristischen Kerne, der vegetative und der generative Kern. Der letztere wird durch eine zarte, uhrglasförmige Membran vom übrigen Raume des Pollenkornes abgetrennt. Es entsteht die linsenförmige, generative Zelle. Ihr Kern zeigt oft entsprechend den beschränkten, räumlichen Verhältnissen eine länglich-ovale Gestalt. Helligkeitsdifferenzen zwischen generativem und vegetativem Kern, hervorgerufen durch größeren Chromatingehalt und dementsprechend intensivere Tinktion des ersteren, konnte 
ich nicht konstatieren. Der vegetative Kern ist stets rund und nimmt im Gegensatz zum generativen, bald nach seiner Entstehung bedeutend an Größe zu. Anfänglich liegt er noch eine Zeit lang der geperativen Zelle an, später wandert er nach der Mitte des Pollenkornes. Er zeigt einen einzigen Nukleolus von bedeutender Größe. Sein Chromatin ist in Gestalt von Körnchen der Kernwand angelagert (Taf. IV, Fig. 9).

Das eben entstandene Pollenkorn ist mit dichtem Plasma gleichmäßig erfüllt. Später, mit zunehmender Größe, tritt eine große, fast das ganze Zellumen einnehmende Vakuole auf, seltener entstehen zwei kleinere Vakuolen. Das Plasma bildet dann nur einen dünnen Wandbeleg, der an dem Pol, wo die Teilung stattfindet, etwas dichter ist. Im reifen Pollenkorn konnte ich nach gleichzeitiger Einwirkung von Jod und Chloralhydrat reichlich Stärkekörnchen nachweisen, die später auch in den auswachsenden Pollenschlauch übertreten.

Die Tapetenzellen sind neben den reifenden Pollenkörnern noch eine Zeit lang sichtbar. Sie zeigen plattenförmige Gestalt und, solange sie als ernährende Organe fungieren, dichtes Plasma. Ihr Kern ist um diese Zeit sehr reich an Chromatin und hebt sich infolgedessen von den Kernen der übrigen Antherenwandzellen durch intensive Tinktion ab. Wenn die Tapetenzellen funktionslos geworden sind, werden sie vollkommen resorbiert. Die ihnen nach außen folgende Schicht hat schon vorher dasselbe Schicksal erfahren. Es bleiben somit nur die beiden äußersten Schichten bestehen, die wohl auch Penzig meint (l. c., pag. 159, wenn er von den Antheren bei Epirrhizanthes cylindrica sagt: „Ihre Wandung ist nur aus zwei Schichten von Zellen, d. h. der Epidermis und einer Schicht Purkinje'scher Zellen gebildet." Letztere zeigen in ihrer definitiven Ausbildung an ihren radialen Wänden Verdickungen. Auf jeder Radialwand treten drei stäbchenförmige Leisten auf, eine mittlere, gegen welche zwei seitliche (nach unten zu) konvergieren, an der reifen Anthere kollabieren die Epidermiszellen stark, die Außenwände legen sich den Innenwänden an und sind nur um die Reste der Kerne noch bucklig vorgewölbt. Vor dem Aufspringen des Staubbeutels beginnt auch die die beiden Pollensäcke trennende Zwischenwand $\mathrm{zu}$ schrumpfen und an einer Stelle zu reißen. Sie ist auch in ihrer vollen Ausbildung nur wenige Zellagen dick. Zur Ausbildung eines Leitbündels kommt es in ihr niemals.

\section{Entwicklung des Embryosackes.}

Im Abschnitt über die Blütenentwicklung wurde schon darauf hingewiesen, daß die Anlage und Ausbildung des Gynäceums später 
und langsamer erfolgt als diejenige der Staubblätter. Während bei jenen schon die Pollenmutterzellen das Synapsisstadium erreicht haben, bildet dieses noch einen einfachen Gewebehöcker, an dem sich weder Fruchtknotenwandung noch Plazenta und Samenanlage unterscheiden lassen. Durch einen im Querschnitt halbkreisförmig erscheinenden Riß hebt sich alsdann die Samenknospe vom übrigen Gewebe des Fruchtblattes $a b$, und bald darauf ist auch die Archesporzelle sichtbar. Sie entsteht in der subepidermalen Zellschicht des Nuzellus und unterscheidet sich zunächst von ihren Nachbarzellen nicht wesentlich durch ihre Größe. Ihr Kern dagegen ist schon jetzt umfangreicher als derjenige der angrenzenden Nuzelluszellen. Seine chromatische Substanz -ist in Gestalt von Körnern, zwischen denen ein Nukleolus sichtbar ist, über den ganzen Kernraum gleichmäßig verteilt (Textfigur $3 a$ ).

Wenn an der Peripherie des Nuzellus die Anlagen des inneren Integumentes sichtbar werden, teilt sich die Archesporzelle in eine neue
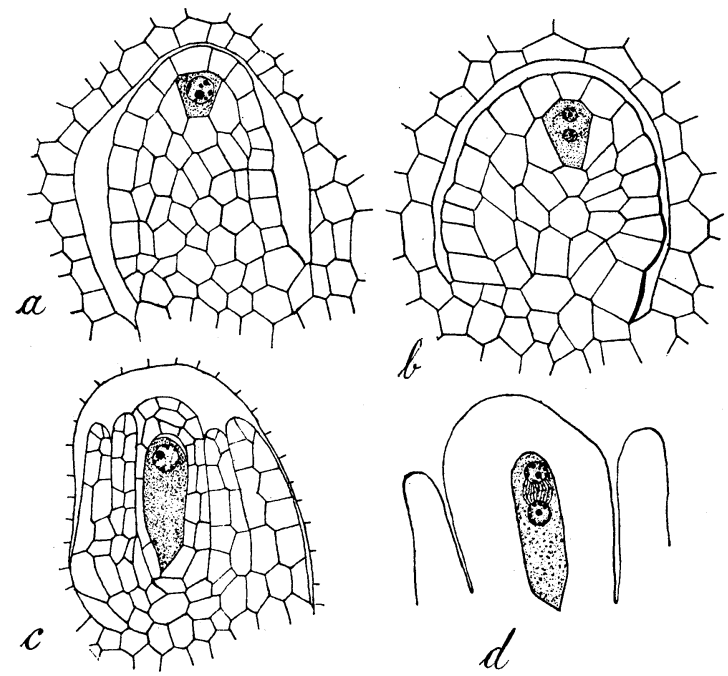

Fig. 3.

a Epirrhizanthes cylindrica. Samenanlage mit subepidermaler Archesporzelle. Vergr. 570/1. $\quad b$ Epirrhizanthes elongata. Kernteilung in der Archesporzelle, die zur Bildung einer subepidermalen Zelle (Tapetenzelle) und der Embryosackmutterzelle führt. Vergr. 570/1. c Epirrhizanthes elongata. Embryosackmutterzelle und Integumente. Vergr. 570/1. d Epirrhizanthes elongata. Erste Teilung der Embryosackmutterzelle. Vergr. $570 / 1$.

subepidermale Zelle (Tapetenzelle) und die Embryosackmutterzelle, die sich bald in der Richtung der Längsachse $\mathrm{zu}$ strecken beginnt. Ihr plasmatischer Inhalt ist dicht und stark färbbar, so daß sie sich deutlich vom umgebenden Gewebe abhebt. Die ausgewachsene Embryosackmutterzelle zeigt eine länglich-rechteckige Form und ist oft an ihrem oberen Ende dachförmig zugespitzt. Ihr Kern, der ebenfalls bedeutend an Größe zugenommen hat, liegt anfangs in der Mitte des Zellraumes, später wandert er in dessen obere Hälfte. Sein Chromatin ordnet sich, 
ähnlich wie wir es schon für die Pollenmutterzelle nachgewiesen haben, zunächst in Gestalt von Körnchen gleichmäßig an die Kernmembran an, und wie dort ist der Nukleolus von einem deutlichen, hellen Hofe umgeben. Die Ausbildung des feinen Fadennetzes erfolgt ungefähr zu der Zeit, wo in den Antheren schon die einkernigen Pollenkörner vorhanden sind. Alsdann kontrahiert sich der Kernfaden zu dem der Kernwand einseitig anliegenden Synapsisknäuel, aus dem das Kernkörperchen ausgestoßen wird. Auf dem Stadium der Synapsis scheint der Kern längere Zeit zu verweilen, wenigstens fand ich dasselbe sehr häufig und viel öfter als die übrigen Entwicklungszustände des Kernes. Wie Textfigur $3 d$ zeigt, erfolgt die erste Kernteilung der Embryosackmutterzelle an der Spitze. In dem hier dargestellten Falle haben sich schon die beiden Tochterkerne mit kleinem Kernkörperchen gebildet. Zwischen beiden sind noch die Reste der Kernspindel sichtbar. Ob durch diese erste Kernteilung die Embryosackmutterzelle in eine vordere, kleine und in eine hintere, größere Tochterzelle zerlegt wird, kann ich nicht sagen. Die Lage der Kernspindel legt eine solche Vermutung nahe, doch kamen mir entscheidende Stadien nicht zu Gesicht. Die Tetradenbildung scheint überhaupt sehr rasch vor sich zu gehen, wenigstens konnte ich an den zahlreichen Präparaten den eigentlichen Kernteilungsvorgang, die Differenzierung der Chromosomen, ihre Anordnung zur Kernplatte und ihr Auseinanderweichen nie beobachten. Im übrigen kommt es in der bekannten Weise zur Ausbildung einer axialen Reihe von vier Tochterzellen, von denen die unterste sich zum Embryosack entwickelt

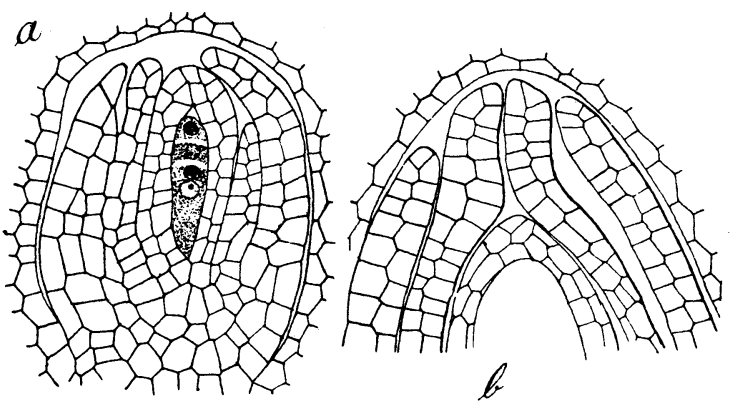

Fig. 4. Epirrhizanthes elongata. a Makrosporentetrade (Zellen in einer Reihe angeordnet). Vergr. 285/1. $b$ Bildung der Mikropyle nur durch das innere Integument. Vergr. 285/1. (Textfigur $4 a$ ). Die drei oberen werden zusammengedrückt und resorbiert. Ihre Reste sind indessen noch sichtbar, wenn die Embryosackzelle schon in das Zweikernstadium eingetreten ist.

Während der Tetradenteilung wölben sich die Integumente, die in Zweizahl zur Ausbildung kommen, allmählich über dem Scheitel des Nuzellus zusammen. Das äußere Integument stellt sein Wachstum 
etwas früher ein. Durch den breiten Kanal, der von demselben umschlossen wird, wächst das innere Integument aufwärts, das allein an der Bildung der Mikropyle beteiligt ist (Textfigur $4 b$ ).

Im einkernigen Embryosack nimmt der Kern bald eine zentrale Lage ein. Er ist länglichoval und enthält ein kleines Kernkörperchen. Seine Längsachse fällt mit derjenigen des Embryosackes zusammen. Das Plasma ist noch gleichmäßig über den ganzen Zellraum verteilt. Den Verlauf der ersten Kernteilung im Embryosack konnte ich nicht verfolgen. Die daraus resultierenden Kerne liegen an den Polen der nunmehr tonnenförmig gewordenen Zelle, je in einer dichten Ansammlung von Plasma. Der größte Teil des Zellumens ist von der einen, großen Vakuole eingenommen (Textfigur 5 a).

Beim zweiten Teilungsschritt stehen die beiden Kernspindeln schief zur "Längsachse des Embryosackes. Aus dieser Tatsache läßt
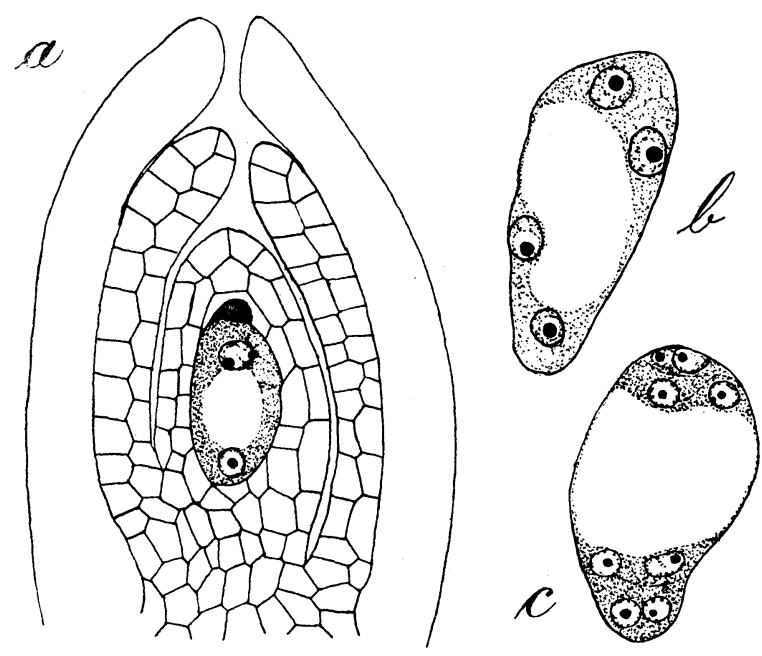

Fig. 5. Epirrhizanthes elongata. a Zweikerniger Embryosack. Am oberen Pole die Reste der drei degenerierten Tetradenzellen. Vergr. 390/1. $b$ Vierkerniger Embryosack. Vergr. 560/1. c Achtkerniger Embryosack kurz nach dem dritten Teilungsschritt. Vergr. 390/1. sich die Lagerung der Kerne während desVierkernstadiums leicht erklären. Zwei von ihnen sind nämlich in den beiden Enden des Embryosackes gelagert, während die beiden anderen (Textfigur $5 b)$ an den Seitenwänden etwas gegen die Mitte der Zelle zu vorgeschoben sind und einander schief gegenüber stehen. Alle vier Kerne sind länglichrund und weisen ein stark färbbares Kernkörperchen auf.

Von den beiden polaren Kernen liefert wohl derjenige des Mikropylarendes die beiden Synergiden, der untere zwei Antipoden; von den beiden mittleren der obere den Eikern und den oberen Polkern, der untere den dritten Antipodenkern und den unteren Polkern. Kernteilungen, die diese Vermutungen bestätigten, konnte ich indessen nicht 
auffinden; ebenso wenig begegnete mir das Stadium der acht freien Kerne, dagegen eine nur wenig ältere Entwicklungsstufe, wo im achtkernigen Embryosack eben um einzelne Kerne sich zarte Plasmawände zu bilden beginnen, eine deutliche Differenzierung des zukünftigen Eiapparates in Synergiden und Eizelle aber noch nicht eingetreten ist (Textfigur $5 c$ ).

In Taf. IV, Fig. 10 u. 11 sind die Elemente des befruchtungsfähigen Embryosackes dargestellt. Am oberen Ende findet sich die große Eizelle. Ihr Kern liegt an der Spitze in eine dichte Plasmaschicht eingebettet. Er ist rundlich und weist ein einziges, nicht sehr großes Kernkörperchen auf. Chromatische Substanz enthält er recht wenig. Der basale Teil der Eizelle wird fast vollständig von einer einzigen, großen Vakuole eingenommen (Taf. IV, Fig. 11) oder es treten zahlreiche kleinere Vakuolen auf, die durch schmale Cytoplasmaschichten voneinander getrennt sind.

Die beiden flaschenförmig gestalteten Synergiden stehen der Eizelle zumeist an Länge nicht viel nach. Die Vakuole, an deren Stelle auch hier mehrere kleinere treten können, liegt, wie dies bei den Synergiden gewöhnlich der Fall ist, am Scheitel. Sie kann, wie Taf. IV, Fig. 10 zeigt, sehr groß werden und nahezu zwei Drittel des Zellumens in Anspruch nehmen. Der Kern der Synergiden liegt in deren basalem, von dichtem Plasma angefüllten Teile und steht dem Eikern an Größe kaum nach.

Die beiden Polkerne trifft man meist in der Nähe der Eizelle einander dicht anliegend. Sie sind kugelrund, platten sich aber an den Stellen, wo sie sich berühren, ab (Taf. IV, Fig. 11). Am häufigsten sieht man die beiden Kerne in einem die Antipoden mit dem Eiapparat verbindenden Cytoplasmastrange senkrecht untereinander liegen (Taf. IV, Fig. 10).

Die acht Kerne des Embryosackes sind kurz nach ihrer Entstehung gleich groß. Im befruchtungsfähigen Embryosacke aber zeigen sie ziemliche Größenunterschiede. Das stärkste Wachstum haben die Polkerne erfahren, namentlich aber ihre Kernkörperchen, welche diejenigen der übrigen Embryosackkerne an Volumen bedeutend übertreffen (Taf. IV, Fig. 10 u. 11). Die chromatische Substanz tritt in den Polkernen wenig deutlich hervor. In einem Falle fand ich die beiden Polkerne stark in die Länge gezogen und an einem Ende leicht keulig erweitert. In der keulig angeschwollenen Partie lag das Kernkörperchen. Diese eigentümlich gestalteten Polkerne befanden sich in der Mitte des Embryosackes der Länge nach nebeneinander liegend (Taf. IV, Fig. 12). 
Die Antipodenzellen zeigen weder nach Größe noch in ihrer Gestalt auffallende Merkmale. Ihre Anordnung richtet sich nach den räumlichen Verhältnissen des Embryosackes. Sie können in einer Reihe nebeneinander liegen, wenn der letztere an seinem unteren Pole breit gerundet ist. In den meisten Fällen läuft aber der Embryosack an seinem unteren Ende ziemlich spitz zu und in dieser schmalen Spitze findet meist nur eine Antipodenzelle Platz, während die beiden anderen etwas weiter oben inseriert sind (Taf. IV, Fig. 10). Die chromatische Substanz tritt in den Kernen der Antipodenzellen, besonders auf älteren Entwicklungsstadien, viel schärfer hervor als in denjenigen der übrigen Embryosackelemente. Sie zeigt dieselbe Anordnung, wie in den Kernen der vegetativen Gewebe, d. h. sie ist in Gestalt von Körnchen gleichmäßig über den Kernraum verteilt. Im Plasma der Antipodenzellen, besonders an deren Spitze, treten zuweilen Vakuolen auf, die bei Epirrhizanthes cylindrica eine ansehnliche Größe erreichen. Die Degeneration der Antipoden tritt verhältnismäßig früh ein. Schon vor dem Eindringen des Pollenschlauches beginnen ihre Zellen zu schrumpfen. Die Reste der degenerierenden, intensiv sich färbenden Kerne sind indessen noch längere Zeit sichtbar. Eine Funktion bei der Zuleitung der Nährstoffe, welche zur Entwicklung des Endosperms und des Embryos notwendig sind, wird man somit den Antipodenzellen auch bei der Gattung Epirrhizanthes nicht zuschreiben können.

\section{Die Bestäubung.}

Wie in dem Abschnitt über die Entwicklung der Antheren beschrieben worden ist, wird die die beiden Pollensäcke trennende Wand durchbrochen, und zwar geschieht dies an der Stelle, wo sie an die gegen den Griffel gerichtete Antherenwandung anstößt. Das Öffnen der Staubbeutel geschieht intrors durch einen über beide Pollensäcke sich hinziehenden Längsriß. Schon Penzig vermutet für Epirrhizanthes Selbstbestäubung (l. c. pag. 159): „Die Bestäubung erfolgt höchstwahrscheinlich autogamisch durch Abstreifen der großen, schweren Pollenkörner an der gleich hoch gelegenen Narbe. Nichts in der Organisation deutet auf Fremdbestäubung." Meine eigenen Beobachtungen können die Richtigkeit dieser Vermutung vollkommen bestätigen. Die Antheren und die kopfförmige Narbe sind stets, auch während der Anthese, von der kahnartigen Carina umhüllt. Die Keimung der Pollenkörner findet innerhalb der Anthere statt, aber erst nach dem Auftreten des introrsen Längsrisses. Textfigur $6 a$ zeigt ein Pollenkorn, das schon innerhalb des Pollensackes einen Schlauch von ansehnlicher Länge ge- 
trieben hat. An der Spitze des letzteren findet sich eine keulige Anschwellung, wie ich sie auch anderwärts, z. B. an Schläuchen, die im Griffelgewebe wuchsen, beobachten konnte. Aus dem weit klaffenden Längsriß sieht man die Pollenschläuche oft in größerer Zahl herauswachsen. Bei Epirrhizanthes cylindrica waren die sich öffnenden Staubbeutel, der Narbe, der sie sich von oben her anlegen, stets dicht angeschmiegt; bei Epirrhizanthes elongata standen sie dagegen oft in einigem Abstande von derselben und die Pollenschläuche mußten, um zur Narbe zu gelangen, diesen Zwischenraum überbrücken. Da konnte es leicht vorkommen, daß sie die Narbe überhaupt nicht erreichten, und in der Tat begegneten mir Schläuche, die auf ziemlich lange Strecken zwischen der sog. Staminalröhre und dem Griffel frei abwärts gewachsen waren. Auch bei Epirrhizanthes elongata kann teilweise ein unmittelbares Anlegen der Antheren an die Narbe konstatiert werden (und zwar geschieht dies im Gegensatz zu Epirrhizanthes cylindrica immer von der Seite her); häufig ist es indessen so, daß nur zwei oder drei der Staubbeutel die Narbe berühren, während die anderen etwas tiefer liegen (Textfigur $6 b$ ).

Auf jüngeren Entwicklungszuständen der Blüte überragt der Griffel die Staminalröhre und wird von dieser in der Länge erst erreicht, wenn im Innern der Staubbeutel die Pollenkörner ihre Reife erlangt haben.

Die Austrittstellen für die Pollenschläuche befinden sich, wie schon früher erwähnt wurde, auf jenem äquatorialen Gürtel des Pollenkornes, der auf Längsschnitten als seitliche Ausbuchtung, die bei Ep. elongata stärker hervortritt als bei der Art cylindrica, sich darstellt. Unmittelbar nach seinem Austritt durch den engen Keimporus erweitert sich der Schlauch bedeutend (Taf. IV, Fig. 13). Sein Plasma ist sehr dicht und färbt sich infolgedessen intensiv. Er enthält zahlreiche Körnchen von derselben Gestalt, wie sie im ruhenden Pollenkorn sich finden. Aller Wahrscheinlichkeit nach sind es Stärkekörner. In dem dichten Schlauchinhalt sind die Kerne nicht leicht zu sehen. Wahrscheinlich verläßt zuerst der generative Kern das Pollenkorn, wenigstens sah ich in einem Falle in einiger Entfernung hinter der wachsenden Pollenschlauchspitze die beiden Spermakerne, denen der vegetative Kern unmittelbar nachfolgte. Die Bildung der Spermakerne durch Teilung des Kernes der generativen Zelle erfolgt erst, nachdem die Pollenkörner zu keimen begonnen haben. In einem Pollenschlauch, der noch nicht aus dem Pollensack herausgewachsen war, konnte ich die Teilung des generativen Kernes beobachten. Die Kernspindel stand dabei parallel 
zur Längsachse des Schlauches. Die entstehenden Spermakerne sind sehr klein und zeigen eine länglich-stabförmige Gestalt (Taf. IV, Fig. 14).

Die kopfförmige Narbe ist mit zahlreichen langen Papillen besetzt. Bei Epirrhizanthes cylindrica trägt sie noch ein besonderes, napfförmiges Anhängsel (Penzig l.c. pag. 160). Die Narbenpapillen sind von Plasma dicht erfüllt. Nur an ihrer Spitze treten kleine Vakuolen auf.

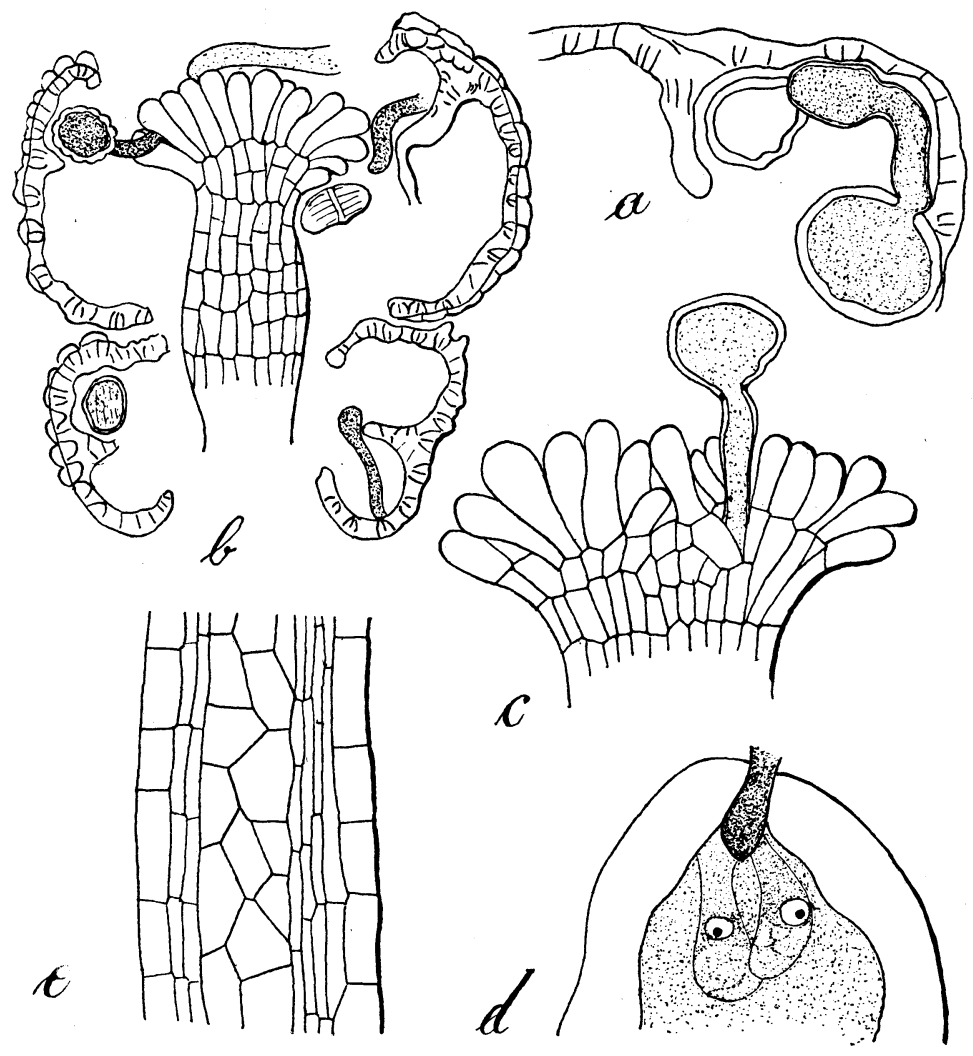

Fig. 6. Epirrhizanthes elongata. a Pollenkorn, das im Inneren der Anthere gekeimt hat. Vergr. 390/1. b Pollenschläuche, aus den Antheren der Narbe zu wachsend. Vergr. 170/1. c Pollenkorn, das auf der Narbe gekeimt hat. Vergr. 390/1. e Längsschnitt durch das Griffelgewebe. Vergr. 560/1. - Epirrhizanthes cylindrica. d Pollenschlauch, in den Embryosack eindringend. Vergr. 590/1.

Der Kern hält sich gewöhnlich in der Mitte des Zellraumes. Diese Papillen scheiden ein reichliches Sekret aus, das wohl klebriger Natur ist.

Es sitzt ihnen in Form kappenartiger Ansammlungen auf, die eine eigentümliche Struktur zeigen. Wo diese Kappen den Papillen anliegen, bildet ihre Substanz eine homogene, dichte Schicht; im übrigen 
zeigen sie ein mehr schwammiges Gefüge. An ihrer Peripherie sind die "Sekretkappen“ anscheinend von einer dichteren Haut umgeben.

Ein Ineinanderfließen der Sekretmassen benachbarter Papillen findet offenbar nicht statt. Diese beiden letzteren Tatsachen legten unwillkürlich die Frage nahe, ob vielleicht eine Abhebung der Cuticula der Narbenpapillen von den übrigen Wandschichten stattgefunden habe und die Absonderung des Sekretes in den so entstandenen Raum hinein erfolgt sei, wie es bei gewissen Drüsenhaaren, z. B. an denen von Pelargonium zonale, der Fall ist. Entwicklungsstadien, die ein allmähliches Abheben der Cuticula zeigten, konnte ich indessen nicht auffinden. Über den scharf abgegrenzten Sekretkappen tritt zur Zeit, da die Pollenkörner keimen, ein schaumiges Gerüstwerk (Taf. IV, Fig. 15) der gleichen Substanz auf, das oft den ganzen Zwischenraum von der Narbe bis zur kuppelförmigen Wölbung der Carina hinauf erfüllt. In den mit Hämatoxylin gefärbten Präparaten hat das Narbensekret keine Färbung angenommen. Es erscheint hier gelblich und stark lichtbrechend. Wenn das Dreifarbenverfahren nach Flemming angewendet wurde, nahmen die „Sekretkappen“ (vom Safranin) einen rötlichen Farbenton an.

Die Pollenschläuche dringen zwischen den Narbenpapillen hindurch (Textfigur $6 c$ ) ins Innere des Griffels ein und durchwachsen interzellulär dessen Leitungsgewebe. Dieses wird bei beiden Arten der Gattung Epirrhizanthes gebildet von einer Säule meist langgestreckter Zellen, die den Griffel von oben bis unten durchsetzt. Vom umgebenden Griffelgewebe heben sich die Zellen des leitenden Stranges deutlich durch ihr größeres Volumen ab. Das zentrale Leitungsgewebe ist von einem mehrschichtigen Mantel langgestreckter, schmaler, aber plasmareicher Zellen umgeben, an den sich nach außen die Epidermis anschließt. Auch da, wo der Griffel in den Fruchtknoten übergeht, findet sich leitendes Gewebe, das sich aus langgestreckt rechteckigen Zellen zusammensetzt, deren Längsdurchmesser aber hier senkrecht zur Griffelachse steht. Ein Bild des anatomischen Aufbaues des Griffels gibt Textfigur $6 e$.

Die Pollenschläuche verlaufen im Griffel nicht gerade nach unten, sondern winden sich zwischen den Zellen hindurch der Samenanlage zu. Das Eindringen in die Mikropyle und das Vordringen des Pollenschlauches durch dieselbe gegen den Embryosack zu, konnte ich mehrfach beobachten. Textfigur $6 d$ zeigt einen Pollenschlauch von Epirrhizanthes cylindrica, der eben das Nuzellusgewebe über dem Eiapparat durchsetzt und im Begriffe ist, in den Embryosack einzudringen. Mit 
seinem zugespitzten Ende scheint er sich der einen der beiden Synergiden zuzuwenden. $\mathrm{Da} B$ er seinen Inhalt in eine derselben ergießt, ist wahrscheinlich. In einem Falle sah ich nämlich den Inhalt der einen Synergide so dicht mit Plasma gefüllt und infolgedessen so intensiv gefärbt, daß in ihrem Innern irgendeine Struktur nicht mehr zu erkennen war, während die daneben liegende Eizelle noch die ursprünglichen Verhältnisse zeigte.

\section{Entwicklung des Embryos.}

Den Befruchtungsakt, das Verschmelzen des einen Spermakernes mit dem Kern der Eizelle einerseits, des zweiten mit dem sekundären Embryosackkern andererseits konnte ich nicht beobachten. Dennoch scheint mir die Befruchtung sehr wahrscheinlich zu sein. Dafür spricht das regelmäßige Eindringen des Pollenschlauches in den Embryosack; dann auch der Umstand, daß die aus den ersten Teilungen des sekundären Embryosackkerns hervorgehenden Endospermkerne deutlich drei

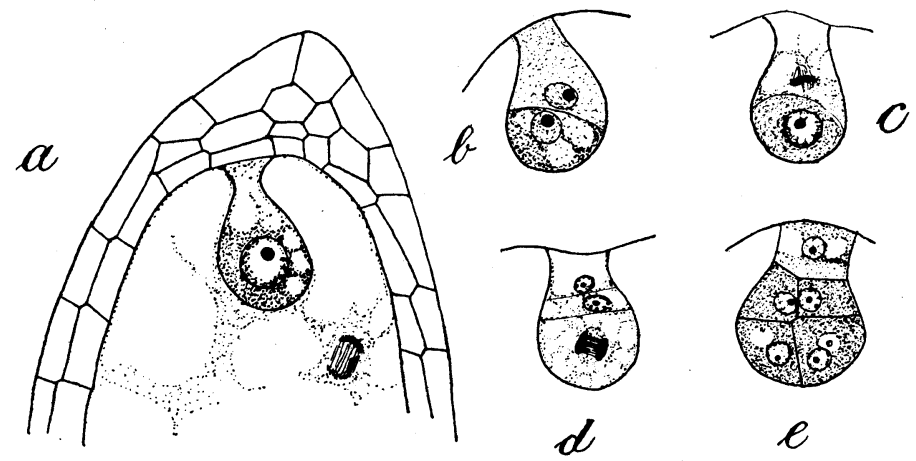

Fig. 7. a Epirrhizanthes elongata. Sich teilender Endospermkern, neben der noch einkernigen Keimzelle. Vergr. 390/1. b Epirrhizanthes elongata. Zweizelliger Embryo. Vergr. 390/1. c Epirrhizanthes cylindrica. Kernteilung in der basalen Zelle. Vergr. 390/1. d Epirrhizanthes cylindrica. Kernteilung in der distalen Zelle des dreizelligen Embryos. Vergr. 390/1. e Epirrhizanthes elongata. Siebenzelliger Embryo; das distale Segment ist durch zwei vertikale Wände vierzellig geworden.

Im zweiten Segment hat sich die erste Vertikalwand gebildet. Vergr. 390/1.

Nukleolen, zwei größere und einen kleineren, besitzen. In dieser Richtung kann vielleicht auch das Auftreten eines zweiten, kleineren Kernkörperchens in der Eizelle, die vor dem Eindringen des Pollenschlauches nur einen Nukleolus besitzt, gedeutet werden.

Die erste Teilung der Eizelle erfolgt in der für die meisten Angiospermen typischen Weise. Die Kernspindel liegt eingebettet in das dichte Plasma des Zellscheitels. Ihre Längsachse fällt mit derjenigen 
der Eizelle zusammen. Durch die im Anschluß an diese erste Kernteilung sich bildende horizontale Wand wird das an Plasma reichere distale Ende der Zelle von einem größeren, plasmaärmeren Basalteile abgetrennt (Textfigur $7 b$ ). Die Synergiden werden, schon bevor die Eizelle zur ersten Teilung schreitet, resorbiert. Die zweite Teilung erfolgt in der Basalzelle, die durch eine horizontale Wand in zwei übereinander liegende Zellen zerlegt wird (Textfigur $7 c$ ). Die weiter nun folgenden Kern- und Zellteilungen führen zur Ausbildung vertikaler Wände. Die erste vertikale Wand tritt in der Scheitelzelle des dreizelligen Embryos auf (Textfigur $7 d$ ). Eine zweite Vertikalwand bildet sich senkrecht zur ersten, so daß die ursprüngliche Scheitelzelle des Embryos in vier Tochterzellen zerlegt wird. Der gleiche Vorgang wiederholt sich etwas später in dem zweiten, unterhalb der Scheitelzelle gelegenen Segmente. Die weiteren Teilungen, die beim raschen Wachstum des Embryos aufeinander folgen, finden hauptsächlich an seinem kugeligen Scheitel statt. Der junge Embryo ist birnförmig; mit zunehmender Größe verändert er aber seine Gestalt. An seinem distalen Ende treten die Anlagen der Keimblätter immer deutlicher hervor. Am ausgewachsenen Embryo haben sie die Gestalt regelmäßig gerundeter Lappen, zwischen denen der Vegetationskegel als schwacher Höcker angedeutet ist(Textfigur $8 c$ ). Die Zellen des letzteren heben sich durch dichteres Plasma und etwas kleinere Kerne vom übrigen Gewebe des Embryos ab. Durch einen zweizelligen Suspensor ist der Embryo an der Wand des Embryosackes be-
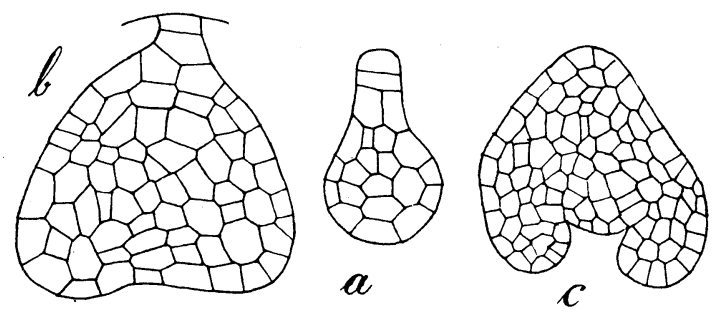

Fig. 8. Epirrhizanthes elongata. a Mehrzelliger Embryo mit zweizelligem Suspensor. Vergr. 285/1. $b$ Vielzelliger Embryo, die beiden Kotyledonen sind als schwache Vorwölbungen am distalen Ende angedeutet. Vergr. 285/1. - Epirrhizanthes cylindrica. c Embryo aus fast reifem Samen mit den beiden Kotyledonen. Vergr. 145/1.

\section{festigt (Textfigur $8 a$}

u. b). Die Anlage der primären Wurzel konnte ich an den von mir beobachteten Embryonen nicht nachweisen. Der wachsende Embryo verdrängt und resorbiert das anfänglich den ganzen Embryosack ausfüllende Endospermgewebe. Um einen Einblick zu bekommen in das Wachstum des Embryosackes während seiner Entwicklung, wurden einige Messungen ausgeführt, deren Resultate in der folgenden Tabelle wiedergegeben 
sind. Bestimmt wurde der Längsdurchmesser auf verschiedenen Altersstadien des Embryosackes.

\begin{tabular}{|c|c|c|}
\hline & $\begin{array}{l}\text { Kleinste } \\
\text { Länge }\end{array}$ & $\begin{array}{l}\text { Größte } \\
\text { Länge }\end{array}$ \\
\hline 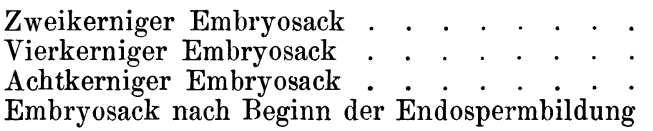 & $\begin{array}{r}42 \mu \\
45 \mu \\
57 \mu \\
120 \mu\end{array}$ & $\begin{array}{r}45 \mu \\
57 \mu \\
120 \mu \\
720 \mu\end{array}$ \\
\hline
\end{tabular}

Aus den obigen Zahlen geht hervor, daß das Wachstum während des zwei- und des vierkernigen Stadiums ein geringes ist. Die Länge der zum erstenmal sich teilenden Embryosackmutterzelle beträgt $40 \mu$, wird also vom zweikernigen Embryosack an Ausdehnung nur wenig übertroffen.

Während des achtkernigen Stadiums verdoppelt der Embryosack seine Länge. Dieselbe beträgt zur Zeit der ersten Teilung des sekundären Embryosackkernes $120 \mu$, im reifen Samen hat sie den Betrag von $720 \mu$ erreicht. Es nimmt somit der Längsdurchmesser während der Ausbildung von Embryo und Endosperm um das Sechsfache zu.

\section{Entwicklung des Endosperms und der Samenschale.}

Noch vor dem Eindringen des Pollenschlauches verschmelzen die beiden Polkerne in unmittelbarer Nähe der Eizelle zum sekundären Embryosackkern. Er ist von beträchtlicher Größe und vollkommen rund. In seinem Innern haben sich die beiden Nukleolen zu einem einzigen großen Kernkörperchen vereinigt, das einen bedeutenden Teil des Kernraumes einnimmt und vakuolige Struktur zeigt. Die chromatische Substanz tritt im ruhenden Kern nicht deutlich hervor. An seiner Peripherie hat sich das Cytoplasma in dichter Schicht gesammelt, und das den größten Teil des Embryosackes einnehmende Vakuolensystem ist um ihn als Zentrum angeordnet. Die Vereinigung des sekundären Embryosackkerns mit dem zweiten Spermakern konnte nicht aufgefunden werden. Seine erste Teilung findet im unteren Teile des Embryosackes, und zwar stets vor der ersten Teilung der Eizelle statt. Die Kernspindel stand in dem von mir beobachteten Falle senkrecht zur Längsachse des Embryosackes. Textfigur $7 a$ zeigt einen sich teilenden Endospermkern neben der noch einkernigen Eizelle. Die ersten Teilungen der Endospermkerne erfolgen langsam. Man trifft schon vielzellige Embryonen zu einer Zeit, wo erst eine geringe Zahl von 
Endospermkernen vorhanden ist. Sie sind anfangs rund oder länglichrund und von bedeutender Größe. In ihrer Umgebung sammelt sich das Cytoplasma meist in größerer Menge an.

Um einen ca. 20zelligen Embryo zählte der Wandbeleg des Embryosackes erst etwa 15 Endospermkerne, die sich offenbar gerade zur Teilung anschickten, denn die chromatische Substanz, die sonst in den Endospermkernen wenig deutlich hervortritt, war in Gestalt scharf umschriebener Körnchen wahrnehmbar. Die Teilungen der Endospermkerne im Wandbelege der verhältnismäßig kleinen Embryosäcke erfolgen gleichzeitig. . Ein Unterschied in den Phasen entfernt voneinanderliegender Kerne läßt sich nicht konstatieren.

Bekanntlich wird bei den Angiospermen das Endosperm auf zweierlei Weise gebildet, entweder durch einfache Teilung oder Fächerung des Embryosackraumes oder dann durch freie Kernteilung mit nachfolgender simultaner Zellbildung. Epirrhizanthes gehört dem letzteren Typus der Endospermbildung an. Es bildet sich ein cytoplasmatischer Wandbeleg mit freien Endospermkernen. Die Ausbildung einer peripheren Schicht von Endospermzellen durch simultane Zellbildung konnte ich allerdings nicht beobachten. Die Endospermzellen stellen ein großmaschiges Gewebe dar, das anfangs den ganzen Embryosack erfüllt und den jungen Embryo rings umhüllt. Sie enthalten stets nur einen Kern, der diejenigen des Embryos und des Nuzellus an Größe überragt. Er nimmt ungefähr die Mitte des Zellraumes ein und ist mit der Zellwand durch strahlig angeordnete Protoplasmafortsätze verbunden. Im Laufe der Entwicklung treten in den anfangs inhaltsarmen Zellen kleine Vakuolen auf, die auf den ersten Blick den Eindruck von Fetttröpfchen machen. Mit der Zeit nehmen dieselben an Zahl und Größe $\mathrm{zu}$ und in den größeren wird bald ein vier- bis fünfeckiges Kristalloid, daneben ein deutliches Globoid sichtbar. Wir haben es also mit Proteinkörnern za tun, wie sie in den Kotyledonen und im Endosperm vieler Pflanzen, in schöner Ausbildung z. B. bei Rizinus, auftreten. Die Proteinkörner treten aus leicht ersichtlichen Gründen zuerst in denjenigen Endospermzellen auf, die der Chalaza zunächst liegen, später in den weiter oben gelegenen und schließlich auch in den Geweben des Embryos.

Wie schon erwähnt wurde, resorbiert der Embryo während seines Wachstums einen großen Teil des ursprünglich den ganzen Embryosack ausfüllenden Nährgewebes. In den reifen Samen umgibt das Endosperm den Embryo seitlich nur noch mit einer einzigen Zellage, während es 
am Grunde des Embryosackes noch in einer Stärke von zwei Schichten auftritt.

Während der Entwicklung des Embryos und des Endosperms erfahren die übrigen Bestandteile der Samenanlage mancherlei Veränderungen. Durch den sich ausdehnenden Embryosack wird - der Nucellus nach außen gedrängt. Er umgibt den Embryosack während der jüngeren Entwicklungsstadien in seinen oberen und mittleren Partien in zweischichtiger in seinen basalen Partien in dreischichtiger Lage. Von diesen Schichten wird zunächst die innerste resorbiert. Die äußerste bleibt am längsten bestehen und ihre, an das innere Integument angrenzende Membran, erfährt eine starke Verdickung und Kutinisierung. Diese kutinisierte Haut ist noch nachweisbar, wenn der Same schon ganz ausgereift ist und die übrigen Bestandteile des Nucellusgewebes völlig resorbiert worden sind. Sie umgibt alsdann das den Embryo umhüllende Endosperm in seiner ganzen Ausdehnung als feste Membran. Das innere Integument wird schon früh zerdrückt und in der Folge vollständig resorbiert.

Am meisten Interesse verlangt die Entwicklung des äußeren Integumentes. Wie das innere besteht es aus zwei Zellschichten, die aber in ihrer weiteren Ausgestaltung sich ganz verschieden verhalten. Die Elemente der inneren Schicht strecken sich zur Zeit, da der Pollenschlauch durch die Mikrophyle dringt, in der Richtung senkrecht zur Längsachse des Embryosackes und vermehren gleichzeitig ihre Zahl durch Längsteilungen ungefähr auf das Doppelte. Diese innere Zellage des äußeren Integumentes erinnert auf diesem Stadium, das Taf. IV, Fig. 17 wiedergegeben ist, an die Entwicklung der innersten Integumentschicht bei den Scrophulariaceen ${ }^{1}$ ) des sog. „Tapetums“. Die Kerne sind in der Mitte des Zellraumes gelagert. Die Zellen zeigen ziemlich dichtes Plasma, das sich um die Kerne etwas stärker ansammelt. Taf. IV, Fig. 18 zeigt ein bedeutend weiter fortgeschrittenes Stadium aus der Entwicklung der „Tapetenzellen“. Sie haben sich in radialer Richtung stark gestreckt, so daß ihr Längsdurchmesser nun ungefähr das Vierfache ihrer Breite erreicht. Damit haben die "Tapetenzellen" ihre definitive Größe erlangt. Sie sind um diese Zeit von gleichmäßig dichtem Plasma erfüllt. Die Kerne haben eine Lageveränderung erfahren und finden sich der äußeren Querwand angelagert. Sie zeigen rundliche bis ovale Gestalt. Die chromatische Substanz tritt in Gestalt von kleinen Körnchen deutlich hervor. Die „Tapetenzellen“ zeigen im

1) Schmid, E., „Beiträge zur Entwicklungsgeschichte der Scrophulariaceen“, Inaugural-Diss. Zürich, Labor. f. allgem. Bot. 1906, pag. 5, Fig. 1 f. 
allgemeinen eine schwache Biegung, deren Konkavseite gegen das Mikropylarende der Samenanlage $\mathrm{zu}$ gerichtet ist. Die weitere Entwicklung des „Tapetums“ führt zu einer stetig zunehmenden Verdickung der Zellmembranen, namentlich der Längswände und der an das Endosperm angrenzenden Querwand, während die zweite Querwand, welcher der nunmehr länglichovale Kern anliegt, und auch die an sie anstoßenden Partien der Längswände unverdickt bleiben (Tafel IV, Fig. 19). Der Zellraum wird infolgedessen immer enger, das Protoplasma mehr und mehr zurückgedrängt. Auf den fortgeschrittensten Entwicklungsstadien ist vom ursprünglichen Zellumen nur noch eine schmale Spalte übrig geblieben. Protoplasma und Kern verschwinden zuletzt vollständig (Taf. IV, Fig. 20). Hand in Hand mit der morphologischen Umwandlung der Wand der Tapetenzellen geht auch eine chemische, die sich schon äußerlich durch eine Änderung in der Farbe dokumentiert. Die verholzten und kutinisierten Membranen werden allmählich gelb, dann zeigen sie eine immer dunkler werdende braune Farbe, die zuletzt in ein intensives Braunschwarz übergeht. $\mathrm{Zu}$ gleicher Zeit wird das Tapetum hart und spröde und zersplittert beim Schneiden leicht. Die Grenzen der an seinem Aufbau beteiligten Elemente sind fast nicht mehr nachweisbar. An der reifen Frucht schimmert das schwarze Tapetum durch das zarte, nicht verholzende Perikarp durch (s. auch Penzig, 1. c. pag. 160). Die äußere Zellage des äußeren Integumentes erleidet wenig Veränderungen. Ihre Zellen folgen dem Wachstum des Embryosackes durch Größenzunahme, nicht durch Vermehrung der Zellenzahl. Sie sind meist länglich-rechteckig, trapezförmig oder fast kubisch und bleiben viel länger lebensfähịg als die Tapetenzellen. Wenn in den letzteren schon eine vollkommene Resorption des Inhaltes erfolgt ist, zeigen Kern und Plasma in den Zellen der äußeren Schicht noch keinerlei Spuren von Degeneration.

Während das „Tapetum" bei Epirrhizanthes elongata gegen das Mikropylarende der Samenanlage gleichmäßig spitz zuläuft (Textfigur $9 a$ ), zeigt dasjenige von Epirrhizanthes cylindrica in seinem oberen Teile eine scharfe Einknickung (Textfigur $9 b$ ).

Das Tapetum umgibt indessen den Embryosack nicht auf allen Seiten in ununterbrochener Schicht. In der Gegend der Chalaza zeigt es eine Lücke. Es ist dies ja leicht begreiflich, denn an dieser Stelle dringt der Nährstoffstrom durch den Nuzellus gegen den Embryosack vor, und für ihn würden die stark verdickten Tapetenzellen ein großes Hindernis bedeuten. Es bleibt also an der genannten Stelle ein Durchgangstor offen (Taf. IV, Fig. 21), das gebildet wird von dünnwandigen, 
parenchymatischen Nuzelluselementen mit dichtem Plasma und kleinen Kernen.

Später, wenn der Zufluß der Nährstoffe von der Chalaza her aufhört, wird diese Durchtrittsstelle geschlossen. Es geschieht dies in

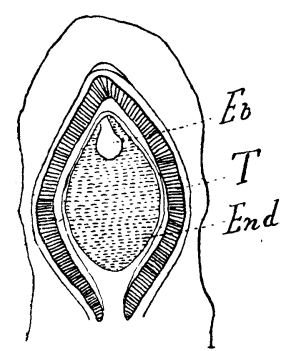

$a$

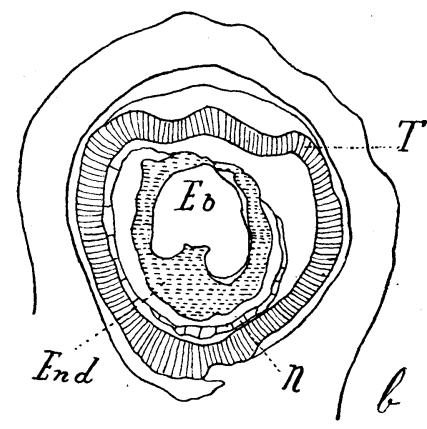

Fig. 9. a Epirrhizanthes elongata. Schnitt durch den noch nicht reifen Samen. Das Endosperm nimmt noch fast den ganzen Embryosackraum ein. Vergr. 70/1. b Epirrhizanthes cylindrica. Längsschnitt durch den reifen Samen. Der Embryo hat einen großen Teil des Endosperms resorbiert. Vergr. 70/1.

Eb Embryo; End Endosperm; $n$ Nuzellus; $T$ Tapetum. interessanter Weise. In den Nuzelluszellen, die an der Stoffleitung beteiligt waren, treten stark lichtbrechende Körnchen auf. Sie erscheinen anfangs spärlich, dann in immer reichlicherer Anzahl, bis dasZellumen davon angefüllt ist. Mit der Zeit zeigt sich auch an diesen Körnchen ein Farbenumschlag von hellem Gelb in ein dunkles Braun, wie wir ihn bei den Tapetenzellen verfolgen konnten.

Die ehemalige Durchtrittsstelle für den Nährstoffstrom im Tapetum ist indessen auch am reifen Samen noch deutlich $\mathrm{zu}$ erkennen. Es macht den Eindruck, als ob hier ein Pfropfen zum Verschluß einer früheren Öffnung nachträglich eingeschoben worden sei. Bei der Bildung dieses „Verschlußpfropfens“ handelt es sich wohl um eine Umwandlung körnigen Plasmas in Membransubstanz.

\section{Beiträge zur Entwicklungsgeschichte von Sciaphila spec.}

\section{Morphologie der Blüten.}

Der Besprechung der morphologischen Blütenverhältnisse möchte ich einige Bemerkungen über die systematische Stellung der hier behandelten Pflanze vorausschicken. Die Gattung Sciaphila gehört zur Familie der Triuridaceen, deren Platz im System noch unsicher ist. Bei Engler u. Prantl ${ }^{1}$ ) ist die Frage, ob diese Familie den Monokotyledonen oder den Dikotyledonen beizuzählen sei, offen gelassen. In

1) Engler u. Prantl, „Die natürlichen Pflanzenfamilien“, II. Teil, 1. Abt. pag. 342, Leipzig 1889. 
Englers $\left.{ }^{1}\right)$ Syllabus der Pflanzenfamilien nehmen die Triuridaceen als die selbständige Reihe der Triuridales zwischen Helobiae und Glumiflorae ihre Stellung ein. Zumeist werden sie jetzt in der Nähe der Alismataceen untergebracht, doch äußert sich Paulsen ${ }^{2}$ ) in einer Arbeit über Triuris major dahin, daß diese Familie ebensogut in die Nähe der Ranunculaceen gestellt werden könne. In einer neueren Studie über Sciaphila nana Bl. läßt derselbe Autor ${ }^{3}$ ) die Frage, ob die Triuridaceen zu den Ranunculaceen oder zu den Alismataceen zu rechnen seien, unentschieden.

Eine genaue Bestimmung der im nachfolgenden besprochenen Art war mir auf Grund der zur Verfügung stehenden Literatur nicht möglich, indessen scheint sie der Gruppe Hyalisma Champ. ${ }^{4}$ ) anzugehören und in dieser wiederum der Sciaphila Andajensis Becc. am nächsten $\mathrm{zu}$ stehen.

Die Blüten sind eingeschlechtig und stehen in traubigen Blütenständen, deren Gipfel von vier bis fünf männlichen Blüten eingenommen wird. Darunter folgen in geringem $\mathrm{Ab}$ stande die weiblichen Blüten, meist in etwas größerer Zahl, auf ziemlich langen Stielen.

Die männlichen Blüten sind sehr klein. Ihr Durchmesser beträgt kaum mehr als ein Millimeter. Das Perianth ist sechszählig, seine Zipfel tragen an ihrer Spitze jenen keulenförmigen Appendix aus plasmareichen Zellen, den Beccari auch für Sciaphila Andajensis und andere Arten dieses Genus beschreibt (l. c. pag. 330): „perianthium lobis lanceolatis apice appendicula elongata et clavata (in alabastro inflexa) praeditis". Die Staubblätter sind in der

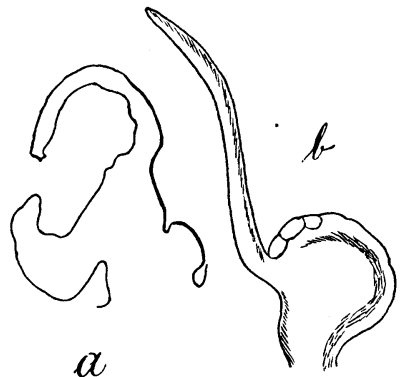

Fig. 10. $a$ Längsschnitt durch ein Staubblatt mit zahnförmigem Gewebehöcker am Grunde. Vergr. 70/1. b Fruchtknoten mit Griffel. Vergr. 70/1. Dreizahl vorhanden. An ihrem Grunde findet sich auf der Innenseite an der Stelle, wo bei Sciaphila Andajensis die sog. Pistillodien entspringen, je ein kleiner Höcker von zahnförmiger Gestalt, der vielleicht als letzter Rest eines Pistillodiums zu deuten ist (Textfigur 10a). Die

1) Engler, A., „Syllabus der Pflanzenfamilien“, Berlin 1907, pag. 82.

2) Poulsen, V. A., „Triuris major spec. nov.", Botan. Tidsskr., Bd. XVII, 1890, pag. 30う.

3) Poulsen, V. A., „Sciaphila nana Bl.“, Meddel. fra den naturh. Foren i. Kbhvn. 1906, pag. 14.

4) Beccari, O., „Malesia“, Vol. III., Firenze-Roma 1886-1890. 
Frage, ob diese Auswüchse der Antheren wirklich als Pistillodien zu betrachten seien, läßt übrigens Beccari noch offen (l. c. pag. 340): "Questo corpo ha l'apparenza di un rudimento di pistillo; ma forse deve come nella Sciaphila crinita Becc. considerarsi come una produzione del connectivo delle antere".

Die weiblichen Blüten, die ein ebenfalls sechszähliges Perianth aufweisen, bestehen aus einer großen Anzahl apokarper Fruchtblätter. Der Griffel ist seitlich, ziemlich nahe der Basis des Karpells inseriert, während er bei Sciaphila Andajensis und überhaupt bei der Gruppe Hyalisma nach Beccari eine mehr apikale Lage hat (l. c. pag. 330): „ovaria in stylum filiforme ad apicem attenuata“. $\mathrm{Er}$ ist fadenförmig und übertrifft den Fruchtknoten an Länge ungefähr um das Doppelte (Textfigur $10 \mathrm{~b}$ ). Seine Epidermis ist wie diejenige des Karpells kaum papillös.

Männliche und weibliche Blüten stehen in der Achsel von Tragblättern.

\section{Entwicklung und Bau der Antheren und der Pollenkörner.}

Die männlichen Blüten erscheinen in ihren ersten Anlagen als kegelförmige Gewebehöcker, über die sich das Tragblatt helmförmig
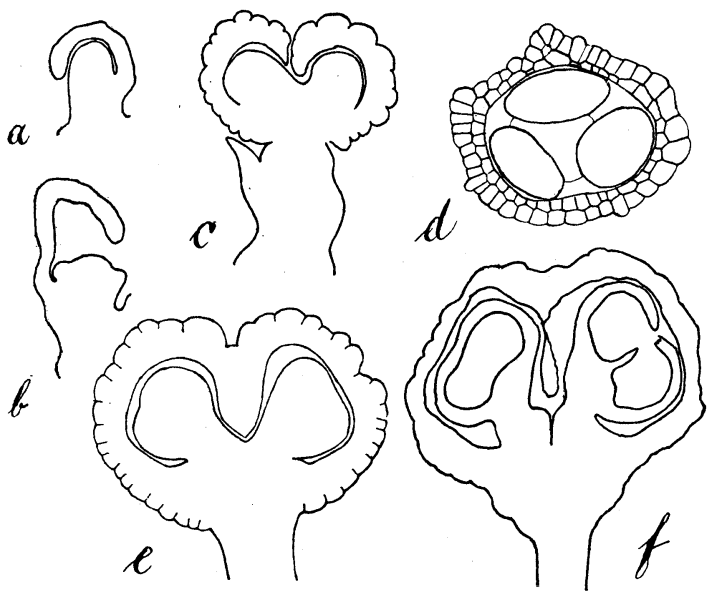

Fig. 11. a Erste Anlage der männlichen Blüte in Form eines kegelförmigen Gewebehöckers. Vergr. 70/1. $b$ Das Perianth beginnt sich als ringförmiger Wulst anzulegen. Vergr. 70/1. $c$ Erste Anlage der Antheren als undifferenzierter Gewebehöcker. Vergr. 70/1. $d$ Das gleiche Stadium im Querschnitt. Vergr. 70/1. e Antheren keulenförmig. Differenzierung in ein kurzes Filament und in eine Anthere. Vergr. 70/1. $f$ Längsschnitt durch eine männliche Blüte mit reifen Antheren. Vergr. 70/1.

hinüberlegt (Textfigur 11a). Letzteres ist zweischichtig. Die morphologisch untere Zellschicht ist stärker entwickelt, die sie zusammensetzenden Zellen sind größer, weisen stärker verdickte Wände auf und. scheinen mit Körnern einer eigentümlichen, hell lichtbrechenden Substanz, 
der wir im folgenden noch des öftern begegnen werden, angefüllt zu sein.

Auf einem etwas späteren Stadium zeigt ein Längsschnitt durch die männliche Blüte seitliche Gewebewucherungen, die sich auf halber Höhe des ursprünglich kegelförmigen Gewebehöckers bemerkbar machen (Textfigur $11 b$ ). Subepidermale Zellen teilen sich senkrecht zur Längsachse der embryonalen Blütenanlage und treiben die Epidermis, die sich als deutliche Zellage vom übrigen Gewebe abzuheben beginnt, nach außen bauchig vor. Dem raschen Wachstum der unter ihr liegenden Gewebe folgt sie durch zahlreiche Zellteilungen.

Die auf dem Längsschnitt als seitliche Ausbuchtungen der Blütenachse erscheinenden Gewebewülste umgeben dieselbe in Form eines äquatorialen Ringes, aus dem sich das Perianth entwickelt. Seine sechs Lappen wachsen rasch empor, den übrigen Bestandteilen der männlichen Blüte um ein Bedeutendes vorauseilend, und wölben sich über dem noch kuppelförmigen Ende des Kurztriebes zusammen. Auch diese Perianthblätter bestehen aus zwei Zellschichten, die anfangs gleiche Ausbildung zeigen. Später erscheinen wieder in den Zellen der Unterseite jene eigentümlichen, körnigen Bildungen stark lichtbrechender Subștanz. Innerhalb der Perianthblätter nimmt das anfangs kuppelförmige Ende der Sproßachse durch seitliches Auswachsen die Gestalt eines ovalen, plattgedrückten Polsters an, von dem sich im weiteren Gange der Entwicklung drei peripher gelegene Gewebehöcker erheben. Während diese randständigen Gewebepapillen sich rasch vergrößern, behält das Polster in seinem inneren, zentral gelegenen Teil die .ursprüngliche Dicke bei. Es kommt so eine Mulde zustande, in die sich die Zipfel der Perianthblätter hineinsenken und sich so dicht aneinander legen, daß man auf den ersten Blick den Eindruck erhält, sie seien miteinander verwachsen. Diese in der Knospe eingeschlagenen (,, in alabastro inflexa", Beccari l. c. pag. 330) Enden der Blütenhülle entsprechen den späteren keuligen Anhängseln (,appendicula elongato clavata“, Beccari l. c. pag. 330) der Perianthblätter, auf die schon im Abschnitt über die äußere Morphologie der Blüte aufmerksam gemacht wurde (Textfigur 11c). Einen Querschnitt durch die männliche Blüte auf dem eben geschilderten Entwicklungsstadium zeigt Textfigur $11 d$. Die drei Gewebehöcker zeigen eine länglichovale Gestalt. Ihr Längsdurchmesser steht tangential zur Längsachse des Blütensprosses.

Aus jedem der besprochenen Gewebehöcker bildet sich in der Folge eine Anthere. Eine Differenzierung verschiedener Gewebekomplexe ist auf dieser Entwicklungsstufe noch nicht eingetreten. Alle 
Zellen sind noch gleichförmig parenchymatisch. Kaum beginnen sich die Epidermiszellen etwas deutlicher vom übrigen Gewebe abzuheben (Textfigur $12 a$ ). Mit der Zeit werden die runden Gewebehöcker keulenförmig, indem sie sich am Grunde etwas einschnüren. Es entsteht eine Partie, die dem auch im ausgewachsenen Zustande sehr kurzen Filament entspricht; aus dem keuligen Ende entwickelt sich natürlich die Anthere (Textfigur 11e). Der Entwicklungsgang der letzteren ist folgender. Subepidermale, durch dichten Plasmainhalt ausgezeichnete

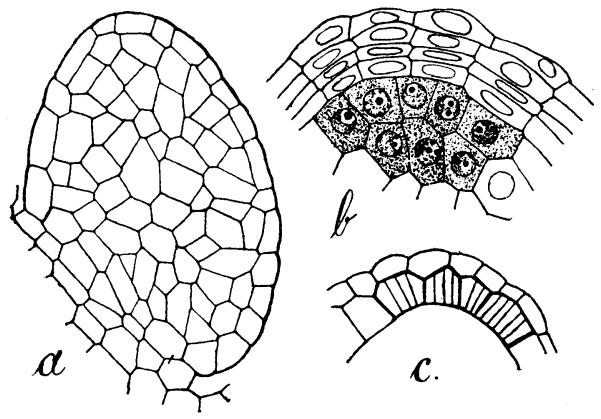

Fig. 12. $a$ Längsschnitt durch ein junges Staubblatt vor der Differenzierung in Filament und Anthere. Vergr. 285/1. $b$ Stück einer älteren Anthere nach Ausbildung der vierschichtigen Wand und der Pollenmutterzellen. Vergr. 410/1. $c$ Stück der Wandung einer reifen Anthere aus Epidermis und fibröser Schicht bestehend. Vergr. $310 / 1$.

Zellen strecken sich in radialer Richtung und teilen sich alsdann periklin. Dadurch entstehen unter der Epidermis zwei Zellschichten von spezieller Bedeutung. Die äußere, neue subepidermale Zellage liefert den größten Teil der späteren Wandung der Pollensäcke, die innere Schicht erzeugt durch weitere Teilungen die Pollenmutterzellen. Durch diese Vermehrung der Gewebe wird die Epidermis der Anthere an vier Stellen über den vier sich bildenden Archesporkomplexen vorgewölbt und dadurch die Entstehung von vier Loculi auch äußerlich, wenn auch nur schwach, angedeutet.

Verfolgen wir zunächst die Bildung der Antherenwandung. Die neue, subepidermale Zellschicht erzeugt durch zweimalige perikline Teilung drei Zellagen, deren Zellen zunächst durchwegs gleiche Größe und Gestalt zeigen. Ihr tangentialer Durchmesser übertrifft den radialen an Länge um das Zwei- bis Dreifache. Die Kerne sind dementsprechend länglich-oval. Ihre Längsachse fällt mit derjenigen der zugehörigen Zelle zusammen. Die Zellen der drei subepidermalen Wandschichten liegen in radialen Reihen und lassen dadurch ihre Abstammung von einer gemeinsamen Mutterzelle deutlich erkennen.

Mit der Zeit gewinnt die innerste Zellage ein etwas anderes Aussehen. Ihre Elemente strecken sich ein wenig in radialer Richtung und füllen sich mit einem feinkörnigen, dichten Plasma. Sie bilden sich zu den Tapetenzellen um, die sich durch ihre intensive Tinktions- 
fähigkeit sofort von den übrigen Wandzellen der Anthere abheben und ein Ernährungsgewebe für die sich teilenden Archesporzellen bilden. Der Kern ist in den Tapetenzellen immer in Einzahl vorhanden und etwas in der Richtung des tangentialen Zelldurchmessers gestreckt. Die Tapetenschicht bleibt ziemlich lange erhalten. Die sie zusammensetzenden Zellen sind noch in unveränderter Gestalt vorhanden, wenn sich die einkernigen Pollenkörner gebildet haben. Später ergießt sich ihr Inhalt, wie ich an mehreren Präparaten beobachten konnte, in der noch geschlossenen Anthere zwischen die Pollenkörner. In der Tat fanden sich denn auch die letzteren im Pollensack in ein Substrat von schleimartiger Konsistenz eingebettet, das bei der Nachfärbung mit Magdalarot eine schwach-rötliche Tinktion annahm. Auf späteren Entwicklungsstadien war diese eigenartige Substanz nicht mehr nachweisbar.

Die auf die Tapetenzellen unmittelbar nach außen folgende zweite Schicht der Antherenwandung wird bald zusammengedrückt. Ihre Reste sind indessen, der äußeren Tangentialwand der Tapetenzellen anliegend als schmale, intensiv sich färbende Lamellen noch eine Zeitlang sichtbar.

Die subepidermalen Zellen der Antheren entwickeln sich zu mechanischen Elementen und bilden die sogenannte „fibröse Schicht". Sie erfahren $\mathrm{zu}$ diesem Zwecke eine Streckung senkrecht $\mathrm{zu}$ ihrem Längsdurchmesser und auf ihren Radialwänden bilden sich Verdickungsleisten, welche in radialer Richtung von der inneren Tangentialwand zur äußeren verlaufen. Die Zahl dieser festigenden Reifen ist verschieden und schwankt zwischen drei und fünf. Oft sind diese Verdickungsleisten gabelig verzweigt (Textfigur $12 c$ ).

An den reifen Antheren sind nur noch die beiden äußeren Wandschichten erhalten, die Epidermiszellen und die darunterliegende ,fibröse Schicht". Erstere sind vielfach geschrumpft und kollabiert, weshalb die Epidermisschicht an vielen Stellen unterbrochen scheint. Tapetenzellen und die zu „verdrängende Schicht" sind spurlos verschwunden.

In den Antheren finden sich regelmäßig vier sporogene Gewebekomplexe. In einem Falle konnte ich nur drei konstatieren. Nach den Untersuchungen von Hemsley ${ }^{1}$ ) scheinen dagegen bei Sciaphila tenella Bl. trilokuläre Antheren die Regel zu sein. Jeder dieser Komplexe enthält zahlreiche sporogene Zellen von regelmäßiger, mehr oder weniger kubischer Gestalt. Der Kern nimmt einen großen Teil des Zellumens ein und übertrifft diejenigen der Antherenwandzellen an

1) Hemsley, B. W., Two new Triuridaceae, with some remarks on the genus Sciaphila Bl.“, Ann. of Bot.. Vol. XXI, 1907, pag. 75. 
Größe um ein Bedeutendes. Er unterscheidet sich auch von ihnen durch seine vollkommene Rundung. In seinem Innern finden sich, von einem hellen Hofe umgeben, zwei bis drei kleine Kernkörperchen. Die chromatische Substanz erscheint auch im ruhenden Kerne in Form kleiner Körnchen, die durch zarte Fäden miteinander verbunden sind.

Während der Vorbereitung der Pollenmutterzellen zur Tetradenteilung konnte ich das Stadium des regelmäßigen Fadennetzes nicht beobachten, wohl aber den Vorgang der Synapsis in seinen verschiedenen Phasen vom lockeren bis zum dichten, kugelförmigen Knäuel, der keine Struktur mehr erkennen ließ. Die Teilung der Pollenmutterzellen ist eine sukzessive, nach der ersten Teilung kommt es zur Ausbildung einer Trennungswand und zur Entstehung zweier Tochterzellen, die sich unabhängig voneinander weiter teilen und die Pollenkörner liefern. Die Pollenentwicklung verläuft also bei Sciaphila ganz nach Art der Monokotylen. Es ist dies ein Grund mehr, die Familie der Triuridaceen in der Klasse der Monokotyledonen, in der Nähe der Alismataceen und nicht bei den Dikotyledonen unterzubringen.

Die der Teilung der Pollenmutterzellen vorangehenden Stadien der Verdoppelung und Segmentierung des Kernfadens konnte ich nicht auffinden. Ebensowenig gelang es mir mit Sicherheit die Zahl der Chromosomen festzustellen, ich vermute aber, daß sie nach der Reduktion zwölf betrage. An vegetativen Kernen ist die Zahl der Chromosomen deshalb schwer zu bestimmen, weil sie ziemlich lang und während der Teilungsphasen vielfach hin- und hergebogen sind.

Die aus der Tetradenteilung hervorgehenden Pollenkörner sind vollkommen rund und von einer verhältnismäßig dicken, ganz glatten Exine umhüllt. Keimporen für den Pollenschlauch konnte ich nie wahrnehmen.

Der Kern der eben entstandenen Pollenkörner zeigt nur wenig chromatische Substanz, die in Gestalt kleiner Körnchen an der Peripherie angeordnet ist. Die Tochterkerne, die durch seine Teilung entstehen, erscheinen anfangs als dunkeltingierte, bohnenförmige Körper. Zunächst ist nicht zu erkennen, welcher derselben zum generativen Kern wird. Mit zunehmender Größe wird aber der eine heller, während der andere durch seinen reicheren Gehalt an Chromatin sich als Geschlechtskern kundgibt. Von einer größeren vegetativen und einer kleineren generativen Zelle kann man kaum sprechen. Das plasmatische Septum teilt den Raum des Pollenkorns in zwei ziemlich gleiche Teile (Fig. 22 u. 23, Taf. IV). 
Die Teilung des generativen Kernes in die beiden Spermakerne findet schon innerhalb des Pollenkornes statt. Die Spermakerne sind länglich, zuweilen schwach kommaförmig gebogen und besitzen ein intensives Tinktionsvermögen (Fig. 24, Taf. IV).

In den kugeligen Pollensäcken entwickeln sich die Pollenkörner, entsprechend den vielen Pollenmutterzellen, in großer Anzahl. Der Durchmesser der reifen Pollenkörner beträgt $15 \mu$. Nachdem die Septen, die die vier Loculi voneinander trennen, resorbiert worden sind, das Innere der Anthere somit von einem einzigen Hohlraum eingenommen wird, öffnet sie sich durch den für die Gattung Sciaphila charakteristischen Längsriß. Auch um diese Zeit schließen die Perianthblätter immer noch über den Staubblättern zusammen (Textfigur 11f). Eigentlich geöffnete männliche Blüten, mit deutlich ausgebreiteten Perianthblättern, traf ich in meinem Untersuchungsmaterial nicht an.

Eine Keimung von Pollenkörnern innerhalb der geöffneten, aber noch nicht entleerten Antheren, konnte ich nicht beobachten.

\section{Entwicklung und Bau der weiblichen Blïte.}

Die weiblichen Blüten nehmen die mittleren und unteren Partien der traubigen Infloreszenzen ein. In ihren ersten Anlagen sind sie von den männlichen wenig verschieden. Wie dort, so bildet auch hier der Scheitel des Kurztriebes einen rundlichen Höcker, der von Perianthblättern überwölbt wird (Textfigur $13 a$ ). Bald dehnt er sich aber stark in die Breite und nimmt die Form einer flachen Scheibe an, auf der zuerst an der Peripherie, dann immer mehr gegen das Zentrum zu die Fruchtblätter entstehen.

Während ich vorliegende Untersuchungen ausführte, kam mir die schon an früherer Stelle zitierte Arbeit von Poulsen zur Hand, in der die eigentümliche Fruchtknoten- und Griffelbildung bei Sciaphila nana Bl., die an jener Pflanze in ganz gleicher Weise verläuft wie bei der von mir bearbeiteten Sciaphila-Art, eingehend beschrieben ist (l. c. pag. 3). Ich möchte daher im folgenden die Entwicklung der Carpelle nur kurz resümieren und im übrigen auf die anschauliche Schilderung des eben erwähnten Autors hinweisen.

Durch lebhafte Teilungen in der Periblemschicht wächst die Spitze der Fruchtblattanlage neben dem an der letzteren eben sich bildenden Nuzelluskegel empor, überholt ihn rasch im Wachstum, wölbt sich über seinen Scheitel hinüber und wächst auf der gegen das Zentrum der Blütenachse zu gerichteten Seite der Nuzelluspapille wieder dem Blütenboden zu (Textfigur $13 b$ u. c). So bildet das Fruchtblatt eine ge- 
schlossene, helmförmige Hülle um den Nuzellus herum. An einer Stelle bleibt indessen längere Zeit eine quergestellte, spaltenförmige, dem

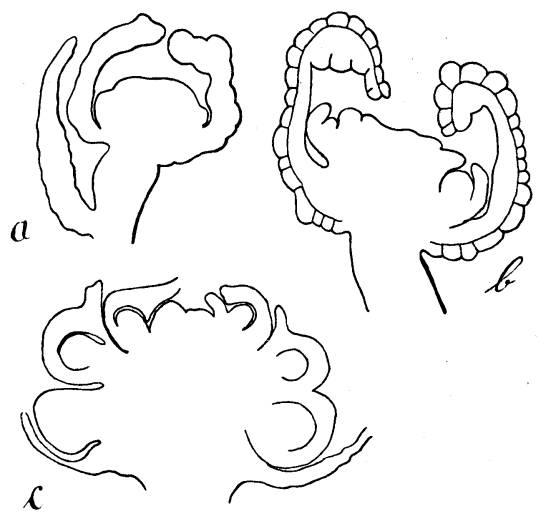

Fig. 13. a Längsschnitt durch die junge Anlage einer weiblichen Blüte vor der Bildung der Carpelle. Vergr. 40/1. $b$ Am Rande der flach-tellerförmigen Blütenachse erheben sich die Anlagen der Carpelle mit den Nuzellushöckern. Vergr. 40/1. c Auf der ganzen Oberfläche des nunmehr gewölbten Fruchtbodens haben sich Carpelle gebildet. Vergr. 40/1. Helmvisier vergleichbare Öffnung, die sogenannte Akropyle, bestehen. In Poulsen's eben zitierter Arbeit gibt Fig. 14 Taf. VI ein klares Bild dieser Verhältnisse. Mit der Zeit wird die Akropyle immer enger. Während der Tetradenbildung im Nuzellus ist sie auf einem Längsschnitt durch den Fruchtknoten nur noch als schmale Spalte nachweisbar (Textfigur 14a). Zur Zeit der Endospermbildung ist die Akropyle vollständig geschlossen, doch ist ihre ehemalige Lage an der Verwachsungslinie ihrer Ränder-noch erkennbar (Textfigur 14b).

Während das Carpell in der geschilderten Weise sich über den Nuzelluskegel hinüberbiegt, schreitet es zur Bildung des Griffels, die sich in gleicher Weise vollzieht wie bei Sciaphila nana Bl. Die wachsende Spitze des Fruchtblattes verbreitert sich fußförmig (Textfigur 15). Die gegen das Zentrum der Blüte gerichtete „Fußspitze“ zieht sich mehr und mehr zu einem drehrunden, säulenförmigen Fortsatz aus, der sich gegen die Spitze zu etwas verjüngt. Der so entstandene Griffel richtet sich aus seiner anfangs horizontalen Lage mehr und mehr auf. In seiner vollen Ausbildung ist er mehr oder weniger über den Fruchtknoten hinüber, gegen den Rand der Blüte zu bogig gekrümmt. Ein ähnliches Verhalten zeigen die ?riffel von Sciaphila crinita (Beccari l. c. Taf. XLII, Fig. 12) und anderer Arten dieser Gattung. Der Griffel zeigt bei der hier besprochenen Art eine schwach papillöse Oberfläche. Er baut sich auf aus langgestreckten, zartwandigen Zellen. Eine Differenzierung seines Gewebes in eimen zentralen, leitenden Strang für die Pollenschläuche und einen peripheren Mantel an der Leitung nicht beteiligter Zellen konnte ich so wenig nachweisen wie Poulsen für Seiaphila nana Bl. (l. c. pag. 10). Auf einem Längsschnitt durch den Griffel erscheinen alle seine Elemente gleichgestaltet. Kaum heben sich die peripheren Zellen durch etwas reicheren Plasma- 
gehalt und durch Einschlüsse körniger Natur, wie sie den meisten Epidermiszellen zukommen, etwas ab. Poulsen konnte an den Griffelpapillen von Sciaphila nana $\mathrm{Bl}$. auch bei lebenden Pflanzen nie keimende Pollenkörner beobachten und möchte aus dieser Tatsache auf eine parthenogenetische Entwicklung der Eizelle schließen (1.c. pag. 12). Auch ich traf nie dem Griffel anhaftende Pollenkörner. Ebensowenig konnte ich jemals einen Pollenschlauch im Griffelgewebe wahrnehmen. Die Griffelpapillen sind

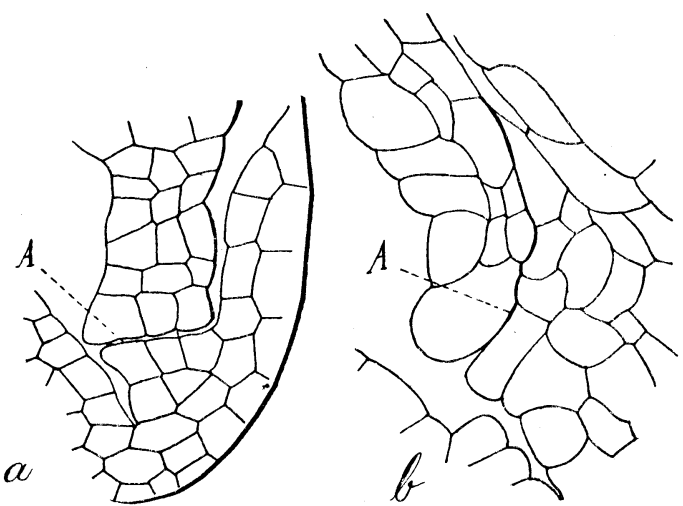

Fig. 14. a „Akropyle“ zur Zeit da sich im Nuzellus die axiale Tetradenreihe gebildet hat. Vergr. 240/1. $b$,Akropyle“ zur Zeit der Endospermbildung (geschlossen). Ihr ehemaliger Verlauf ist durch die stärker ausgezogene Linie angedeutet. Vergr. 240/1. an der vorliegenden

Sciaphila-Art viel schwächer ausgebildet als bei Sciaphila nana Bl., ferner ist der Griffel als Ganzes viel schmächtiger als bei jener Art, so daß ein Zweifel an seiner Funktionsfähigkeit noch eher berechtigt erscheint als dort.

Die Wandung des Fruchtknotens besteht aus drei bis vier Zellschichten. Die einzelnen Zellen sind länglich rechteckig, in der äußersten Zellage viel größer als in den drei inneren. Dadurch fällt die Epid’rmis sofort auf und noch mehr durch die eigentümliche, stark lichtbrechende Substanz, die in ihren Zellen in besonders reichıther Menge und typischer Ausbildung auftritt. Auf den ersten Blick er-

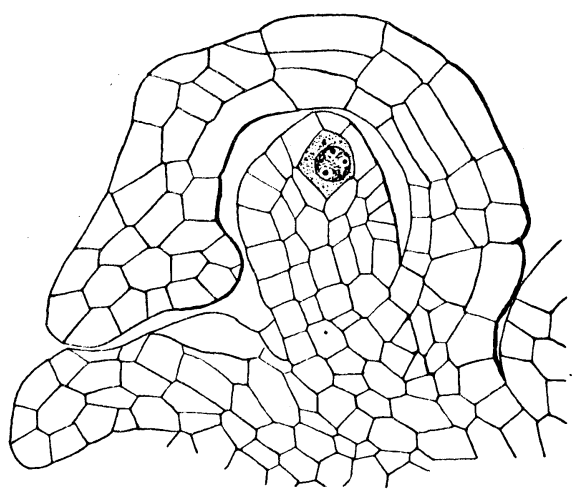

Fig. 15. Das sich über den Nuzellus hinüberbiegende Fruchtblatt hat sich an seiner Spitze fußförmig verbreitert. Der in der Figur nach links sehende Teil des Fußes wächst später zum Griffel aus. Vergr. 285/1. scheinen die Zellen mit stärkekornartigen Einschlüssen dicht angefüllt. Die Körner sind in derselben Zelle meist von ungefähr gleicher Größe. Ihr Volumen kann aber in 
unmittelbar nebeneinander liegenden Zellen stark variieren. Eine genauere Untersuchung zeigt, daß es sich nicht um frei in der Zelle liegende Substanzpartikelchen handelt, daß vielmehr die Zellwände, die mit diesem stark lichtbrechenden Stoffe imprägniert sind, oft sehr regelmäßige, körnchenartige Verdickungen áufweisen.

Die Ausscheidung der besagten Substanz erfolgt schon früh. Noch ehe sich das Carpell um den Nuzellus völlig geschlossen hat, erscheinen in den epidermalen Zellen, unmittelbar hinter der wachsenden Spitze, jene körnigen Membranverdickungen. Ihr Lichtbrechungsvermögen ist anfangs nicht so intensiv, wird aber stärker, je weiter die Epidermiszelle von der Spitze der Carpells entfernt ist. Auch die Kerne der Epidermiszellen imprägnieren sich mit der lichtbrechenden Substanz. Sie verlieren dabei mehr und mehr ihre Tinktionsfähigkeit, werden zuletzt gleich stark lichtbrechend wie die Zellmembranen, lassen aber ihre Form noch deutlich erkennen. Auch das Kernkörperchen ist an den so veränderten Kernen noch deutlich wahrzunehmen.

Wahrscheinlich geht die Ausscheidung der besprochenen Substanz Hand in Hand mit dem Absterben der Zellen. Aber nicht alle abgestorbenen Zellen sind mit ihr imprägniert. Vielmehr ist ihre Ausscheidung auf die peripher gelegenen Zellen beschränkt. Das Vorkommen dieser Substanz als Ausscheidung innerhalb der Membran ließ an Gerbstoffe denken, doch ergab sie bei Einwirkung von Eisensalzlösungen nicht die für jene charakteristischen Reaktionen. Mit Phloroglucin-Salzsäure und schwefelsaurem Anilin erfolgen auch nicht die für Verholzung typischen Färbungen. In konzentrierter Schwefelsäure war die besagte Substanz auch bei längerer Einwirkung unlöslich. Allem Anschein nach handelt es sich also um eine Kutinisierung.

\section{Entwicklung des Embryosackes.}

Während sich das Fruchtblatt über den Nuzellus hinüberwölbt, wird am Scheitel des letzteren eine subepidermale Zelle sichtbar, die sich von ihren Nachbarzellen durch ihr größeres Volumen unterscheidet. Es ist die Archesporzelle. Ihr Plasma ist anfangs wenig dichter als dasjenige der übrigen Nuzelluszellen. Der Kern nimmt einen großen Teil des Zellraumes in Anspruch. Die chromatische Substanz tritt in Form kleiner Körnchen, die durch feine Fäden miteinander verbunden sind, nicht stark hervor. An Größe übertrifft der Kern der Archesporzelle diejenigen der Nachbarzellen bedeutend (Textfigur 16a).

Die ausgewachsene Archesporzelle hat eine länglich-rechteckige Gestalt. Der Kern liegt stets in ihrer oberen Hälfte und•macht hier 
die seiner Teilung vorausgehenden Veränderungen durch. Von den an seiner Peripherie gelegenen Chromatinkörnchen spinnt sich ein zartes, nicht sehr dichtmaschiges Netz von Lininfäden aus, auf das später die chromatische Substanz hinaustritt (Fig. 25, Taf. IV).

Alsdann ballt sich dieses Kerngerüst zu einem dichten Knäuel zusammen, der einseitig der Wand anliegt (Textfigur $16 c u$ u. $d$ ). Der

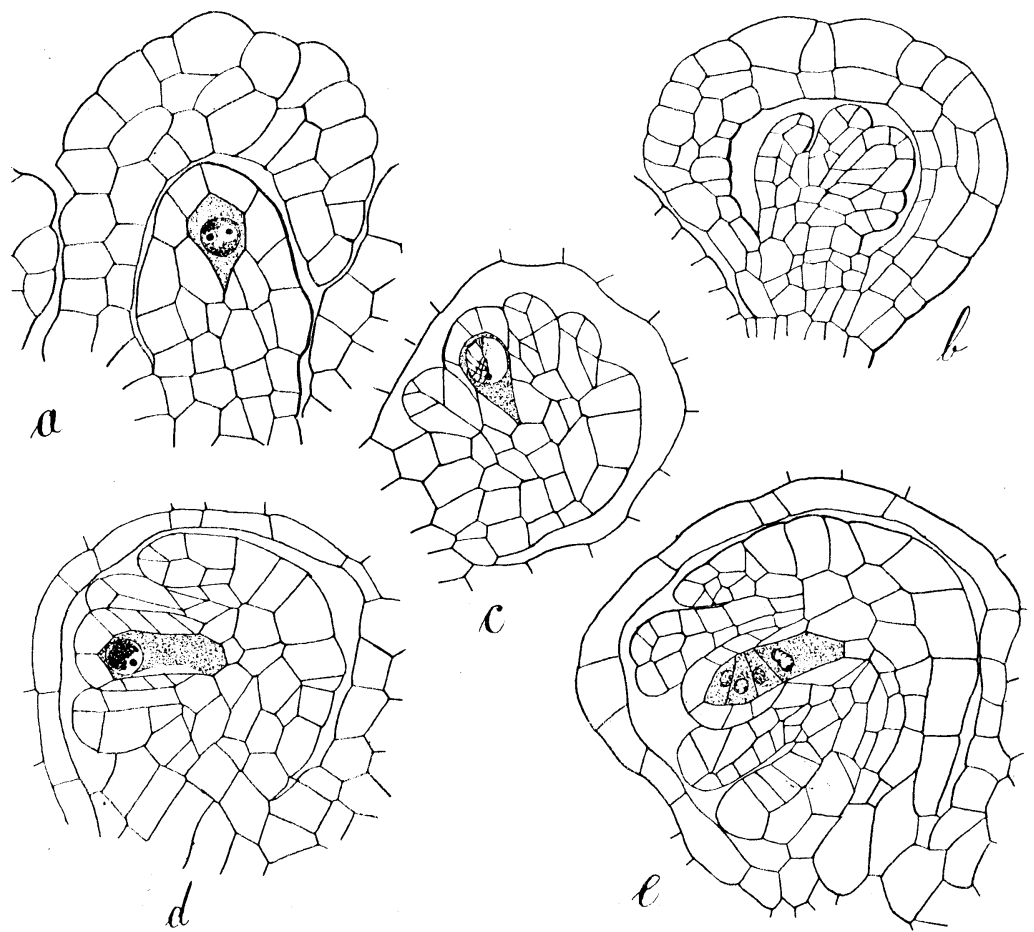

Fig. 16. a Junge, noch aufrechte Samenanlage; Archesporzelle subepidermal. Vergr. 285/1. b Beginnende anatrope Krümmung der Samenanlage. Vergr. 285/1. c Die Samenanlage hat sich um $90^{\circ}$ gedreht; Archesporzelle mit beginnender Synapsis. Vergr. 285/1. d Embryosackmutterzelle im Stadium des dichten Synapsisknäuels ihres Kernes. Vergr. 285/1. e Tetradenbildung. Die Samenanlage hat eine nahezu anatrope Lage angenommen. Vergr. 285/1.

Synapsisknäuel ist kugelförmig und läßt, wenn er seine höchste Ausbildung erreicht hat, keinerlei Struktur mehr erkennen. Die Kernkörperchen werden ausgestoßen und verschwinden bei der Ausbildung der Kernspindeln. Letztere traf ich mehrmals im Längsschnitt. Textfigur $17 a$ zeigt ein solches Stadium der ersten Kernteilung in der Archesporzelle. Das Plasma hat sich an den Spindelpolen zu dichteren Massen angesammelt, während es im übrigen Zellraum nur spärlich 
vorhanden ist. Die Chromosomen haben die Gestalt kurzer, dicker Stäbchen. Ihre Zahl konnte ich auch hier nicht feststellen.

Den Verlauf des zweiten Teilungsschrittes der Tetradenteilung konnte ich nicht beobachten, wohl aber traf ich oft die axiale Reihe der vier Tetradenzellen. Die sie trennenden Wände sind häufig nicht parallel, woraus man schließen muß, daß die Kernspindeln der Teilungen, die zur Bildung der Tetrade führen, sich nicht immer genau in die Längsachse ihrer Zellen einstellen (Textfigur 16e). Von den vier Tetradenzellen entwickelt sich die unterste zum Embryosack weiter, indem sie sich stark verlängert und ihre Schwesterzellen verdrängt.
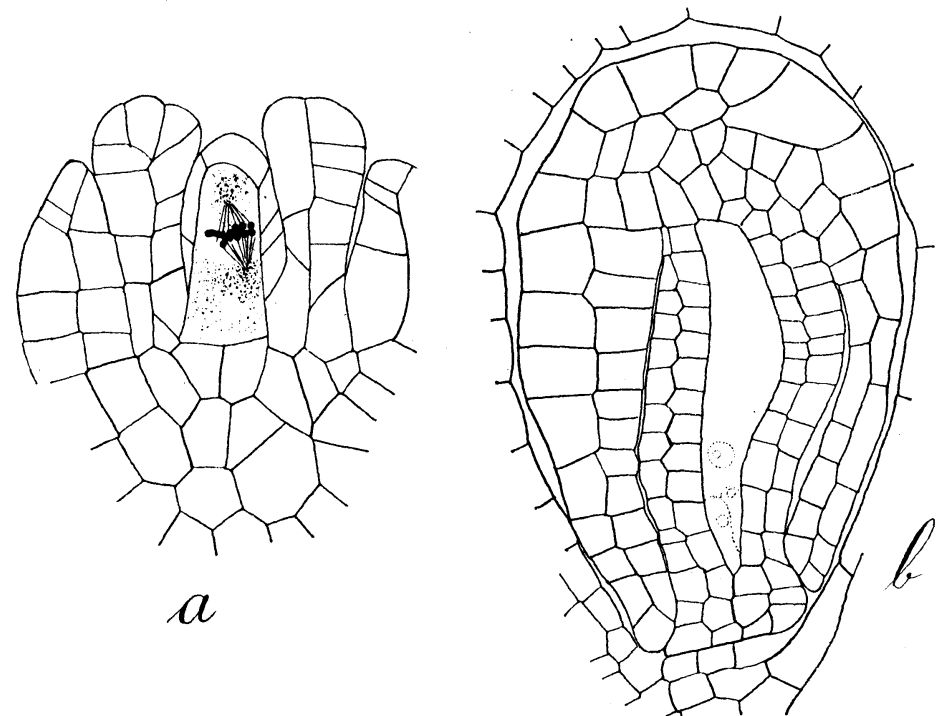

Fig. 17. $a$ Erste Teilung der Archesporzelle. Vergr. 410/1. $b$ Übersichtsbild einer älteren, anatropen Samenanlage. Vergr. 285/1.

Auch am Nuzellus gehen, während die Embryosackmutterzelle die geschilderte Entwicklung durchmacht, verschiedene Veränderungen vor sich. An seiner Peripherie bildet sich nahe der Basis ein ringförmiger Wulst - die Anlage des inneren Integumentes -, der während des Synapsisstadiums, das auch hier, wie in den Pollenmutterzellen ziemlich lange dauert, deutlicher hervortritt und um den Nuzelluskegel als geschlossener Wall emporwächst. Fast gleichzeitig erscheint als zweiter Gewebewulst, wenig unterhalb des ersten, die Anlage des äußeren Integumentes. Während des Tetradenstadiums wächst das innere Integument über den Nuzellusscheitel empor bis an die kuppelförmige Wölbung des Fruchtblattes und die anfangs vorhandene Mikropyle be- 
ginnt sich bald zu verengern. Poulsen (l. c. pag. 13) gibt auch für Sciaphila nana Bl. zwei Integumente an, und wie dort ist auch bei der hier vorliegenden Sciaphila-Art das äußere Integument kürzer und seine Ränder kommen nicht zum Schluß, so daß die Mikropyle, die sich übrigens mit der Zeit vollkommen schließt, vom inneren Integument allein gebildet wird. Beide Integumente sind zweischichtig. Das innere zeigt während der Entwicklung des Embryosackes in seinen Zellen starken Plasmagehalt und sticht infolgedessen vom äußeren auf den ersten Blick durch dunklere Färbung ab. Das äußere Integument beteiligt sich, wie später gezeigt werden soll, am Aufbau der Samenschale. In seiner peripheren Schicht zeigen die Zellen reichlich, die an früherer Stelle besprochenen, stark lichtbrechenden Ausscheidungen.

Die Samenanlage ist ursprünglich orthotrop, später wird sie anatrop. Das allmähliche Umbiegen innerhalb der Fruchtknotenhöhle läßt sich bei Sciaphila sehr schön verfolgen. Es geht zu gleicher Zeit wie die Ausbildung der Integumente vor sich. Wenn sich die Archesporzelle zum ersten Male teilt, hat die Samenanlage schon ihre definitive anatrope Stellung erreicht. Die Richtung der Drehung ist der Biegung des Fruchtblattes um den Nuzellus herum gerade entgegengesetzt. Sie kann vielleicht als eine zentrifugale, dem Rande des Fruchtbodens zugewandte, bezeichnet werden. Die „Akropyle“ befindet sich auf der Funikularseite der Samenanlage. Einige Stadien aus dem Verlaufe dieser Umbiegung sind in der Textfigur $16 a-e$ wiedergegeben. Auch Poulsen (l. c. pag. 13) macht bei Sciaphila nana Bl. auf diesen Übergang der anfangs orthotropen Samenanlage in die anatrope Lage aufmerksam. In der sich stark verlängernden untersten Zelle der Tetradenreihe liegt der Kern in der Nähe der oberen Querwand. Seine Teilung konnte ich nicht beobachten, wohl aber mehrmals den zweikernigen Embryosack, an dessen Polen die beiden Kerne gelagert sind. Die letzteren sind wenig größer als die Kerne des umgebenden vegetativen Gewebes und enthalten zwei bis drei Nukleolen. Der Plasmagehalt des Embryosackes ist um diese Zeit gering. Um die beiden Kerne lagert sich Plasma in etwas größerer Menge an, an den Längswänden ist ein Belag kaum wahrnehmbar. Eine kleine dunkle Kappe am oberen Pol entspricht den Resten der degenerierten Tetradenzellen (Textfigur 18a). Die Zellen des den Embryosack in einer einzigen Schicht umgebenden Nuzellus erscheinen schon jetzt zusammengedrückt und beginnen $\mathrm{zu}$ degenerieren. Sie werden später vollständig resorbiert.

Schon auf dem vierkernigen Stadium zeigt der Embryosack die langgestreckt-keulige Gestalt, die er bis zur Endospermbildung beibehält. 
Er läuft gegen das Antipodenende spitz zu und verbreitert sich allmählich gegen sein oberes Ende. Später wird diese keulige Form durch Veränderungen in benachbarten Geweben modifiziert.

Beim zweiten Teilungsschritt, der zur Entstehung des vierkernigen Embryosackes führt, nehmen die Kernspindeln eine Stellung ein, wie sie Fig. $18 b$ zeigt. Die am breiteren Pole, dem späteren Eipol gelegene steht etwas schief zur Längsachse des Embryosackes. Demgemäß findet
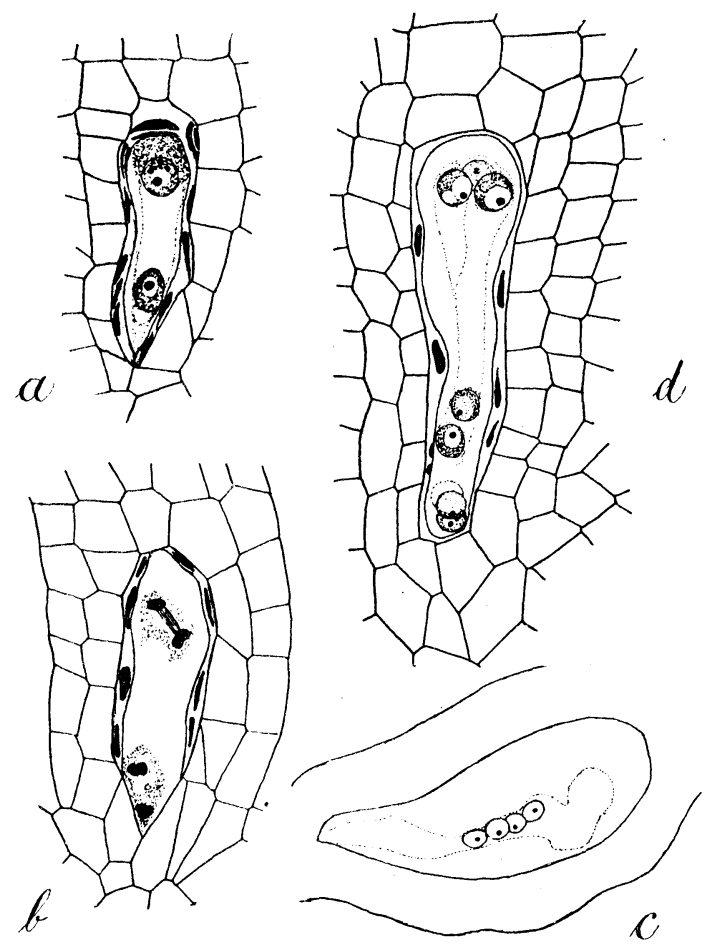

Fig. 18. a Zweikerniger Embryosack. Vergr. 410/1. $b$ Vierkerniger Embryosack. Vergr. 410/1. c Vierkerniger Embryosack (offenbar abnormaler Verlauf der Entwicklung). Vergr. 410/1. d Achtkerniger Embryosack kurz nach Verlauf der dritten Kernteilung. Um die Kerne des Eiapparates und der Antipoden haben sich noch keine Zellen gebildet. Vergr. 410/1.

hen von den vier Kernspindeln je zwei zusammengehörige senkrecht aufeinander.

Die beiden, dem oberen und unteren Pol direkt anliegenden Teilungsfiguren stellen sich senkrecht zur Längsachse des Embryoeinen der beiden dieser Teilungsfigur entstammenden Kerne, dem oberen Ende des Embryosackes anliegen; während der andere etwas tiefer der Seitenwand sich anlagert. Die im spitzen Ende liegende Spindelfigur stellt sich in die Richtung der Längsachse des Embryosackes ein. Die beiden Kerne, die sie liefert, liegen daher stets senkrecht untereinander, während die beiden Kerne des oberen Poles oft auch nebeneinander getroffen werden. Es erklären sich diese verschiedenen gegenseitigen Stellungen der Kerne ja leicht aus den räumlichen Verhältnissen.

Beim dritten. Teilungsschritt, der zur Ausbildung des achtkernigen Embryosackes führt, ste-

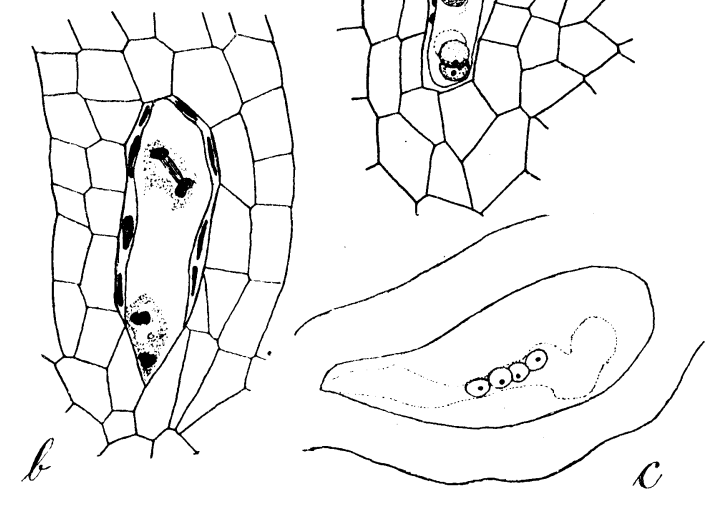

man in der Folge den 
sackes. Sie liefern wahrscheinlich einerseits die Synergiden, andererseits zwei der Antipoden. Die beiden anderen, mehr gegen die Mitte des Embryosackes zu liegenden Teilungsfiguren fallen in ihrer Richtung mit der Längsachse des Embryosackes zusammen und liefern wohl die dritte Antipode und den unteren Polkern, ferner den oberen Polkern und den Eikern.

Textfigur $18 d$ zeigt die durch den dritten Teilungsschritt gebildeten acht Kerne kurz nach ihrer Entstehung. Um die einzelnen Kerne haben sich noch keine Membranen gebildet. Am breiten Eipol liegen die drei Kerne, die den Eiapparat liefern werden. Die beiden Polkerne haben sich in der Nähe des Antipodenendes einander genähert. Die acht Kerne haben ungefähr gleiche Größe und übertreffen diejenigen der umliegenden Gewebe kaum an Volumen. Sie sind in der Eiregion vollkommen rund; der eine der beiden Polkerne zeigt etwas längliche Gestalt. Die Nukleolen sind in der gleichen Zahl vorhanden wie in den vegetativen Zellen und von einem weiten, hellen Hofe umgeben. Die chromatische Substanz zeigt die gleiche Anordnung wie dort und tritt auch nicht in größerer Menge auf.

In der Umgebung des Embryosackes sind, durch sein starkes Wachstum weit auseinandergerückt, die dunkel-tingierten Reste der Nuzelluszellen sichtbar, die ihn ehemals um-

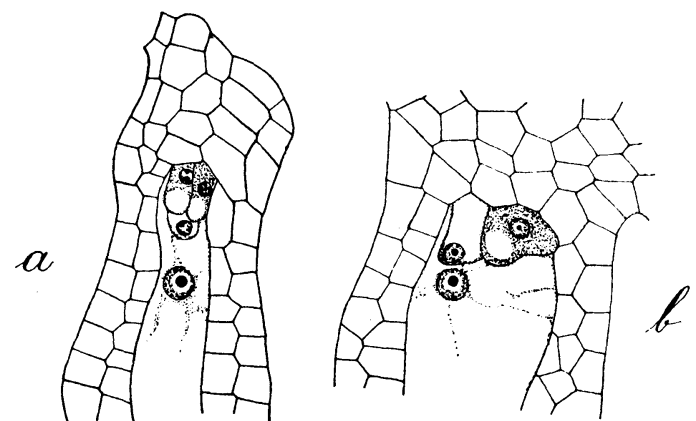

Fig. 19. a Embryosack mit Eiapparat und sekundärem Embryosackkern. Vergr. 285/1. b Eiapparat aus Eizelle und einer Synergide. Vergr. 285/1. gaben.

Der Eiapparat liegt am breiteren Pole des Embryosackes. Die Eizelle ist gewöhnlich etwas länger als die beiden Synergiden. Auffallend ist ihre Plasmaarmut. Ihr Lumen wird fast vollständig von einer einzigen großen Vakuole eingenommen. Nur an ihrem Scheitel, dem der Kern anliegt, zeigt sich ein etwas dichterer Plasmabelag. Der Kern ist rund und nicht größer als derjenige der Synergiden und wie diese eher kleiner als die Kerne des inneren Integumentes. Die Synergiden selbst zeigen keinerlei Besonderheiten. Sie sind länglich-sackförmig gestaltet. Ihr vorderes Ende wird von einer großen Vakuole eingenommen, die oft fast die Hälfte des Zellraumes in Anspruch nimmt. 
Im basalen, mit dichtem Plasma erfüllten Teile liegt der Kern. In einem Falle fand ich nur eine Synergide-ausgebildet, die aber viel größere Dimensionen aufwies. Sie war so lang und fast doppelt so breit als die benachbarte Eizelle. Der Kern allerdings wies nicht größeren Umfang auf als unter normalen Verhältnissen (Textfigur 19b).

Kurz nach der Ausbildung der acht freien Kerne im Embryosack findet man die beiden Polkerne in der Antipodenregion einander genähert. Hier findet auch die Verschmelzung statt. Das Verschmelzungsprodukt, der sekundäre Embryosackkern, wandert alsdann gegen den Eiapparat hinauf. Der sekundäre Embryosackkern zeigt meist nur ein einziges, ansehnliches Kernkörperchen (Textfigur 19a): Er ist anfangs vollkommen rund; später nimmt er eine länglichovale Gestalt an. Von ihm aus strahlen schwache Protoplasmastränge.

Die Antipodenzellen sind klein und unbedeutend. Ihre Lage ist, in Anpassung an die räumlichen Verhältnisse, eine verschiedene. Oft findet man sie in dem engen Sacke in einer Reihe senkrecht übereinander liegen. In anderen Fällen hat die eine der Antipoden in dem spitzen Ende Platz gefunden, während die beiden anderen etwas höher, wo der Embryosack sich zu erweitern beginnt, nebeneinander inseriert sind, so daß eine dreieckige Gruppe zur Ausbildung kommt (Textfigur $20 d$ ).

Schon früh beginnen die Antipodenzellen zu degenerieren. Ihre Kerne schrumpfen und der übrige Zellinhalt wird stark lichtbrechend. Die Reste der Antipodenzellen sind indessen noch zu einer Zeit sichtbar, wo sich schon zahlreiche freie Endospermkerne gebildet haben (Textfigur $20 d$ ). Eine Funktion bei der Zuleitung der Nährstoffe wird man also den Antipoden kaum zuschreiben können; zudem zeigen die den Embryosack begrenzenden Elemente zuerst gerade am Antipodenpol eine Verdickung und Verholzung ihrer Membranen. Eher dürfte dem inneren Integument als Ganzem eine Rolle bei der Ernährung des Embryosackes zukommen, worauf der starke Plasmagehalt seiner Zellen hindeuten mag.

Die folgende Tabelle gibt einen Überblick über die Maßverhältnisse des Embryosackes während verschiedener Entwicklungsstadien.

\begin{tabular}{|c|c|c|}
\hline & $\begin{array}{l}\text { Kleinste } \\
\text { Länge }\end{array}$ & $\begin{array}{r}\text { Größte } \\
\text { Länge }\end{array}$ \\
\hline 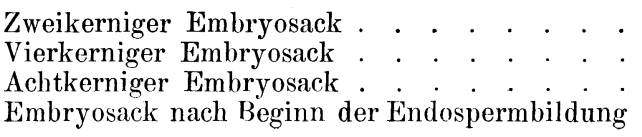 & $\begin{array}{r}51 \mu \\
69 \mu \\
123 \mu \\
210 \mu\end{array}$ & $\begin{array}{r}58 \mu \\
75 \mu \\
176 \mu \\
430 \mu\end{array}$ \\
\hline
\end{tabular}


Aus obiger Zusammenstellung geht zunächst hervor, daß der Embryosack nicht ein während seiner ganzen Entwicklung gleichmäßig fortschreitendes Wachstum zeigt; es scheint vielmehr, daß auf späteren Stadien sein Wachstum intensiver wird. Während des zweikernigen Stadiums ist die Längenzunahme ganz unbedeutend, ebenso während des Überganges zum vierkernigen Stadium und auch innerhalb der Dauer des letzteren ist eine Verlängerung kaum bemerkbar. Etwa $120 \mu$ beträgt die Länge des Embryosackes kurz nach der dritten Kernteilung. Es muß also während der letzteren oder kurz darauf eine starke Streckung stattgefunden haben, denn der längste vierkernige Embryosack maß nur $75 \mu$. Als höchsten Betrag für den Längsdurchmesser eines achtkernigen Embryosackes fand ich $176 \mu$. Es nimmt der achtkernige Embryosack während seines Bestehens an Länge um ein Bedeutendes zu. Die höchsten Werte erreicht aber das Wachstum nach (ler ersten Teilung des sekundären Embryosackkernes während der Entwicklung des Endosperms. Zurzeit, da sich eben die beiden ersten Endospermkerne gebildet haben, beträgt die Länge des Embryosackes $210 \mu$. Wenn die Zahl der Endospermkerne auf ca. 10 angestiegen ist, mißt der Längsdurchmesser $250 \mu$, und wenn Embryo und Endosperm ihre vollkommene Ausbildung erreicht haben, beträgt die Längenausdehnung vom Ei- bis zum Antipodenpol ca. $430 \mu$. Es hat sich somit in der Zeit vom Beginn bis zur Vollendung der Endospermbildung die Länge des Embryosackes gerade verdoppelt.

Auch im ausgewachsenen Samen zeigt der Embryosack eine Verjüngung gegen den Antipodenpol hin, allerdings nicht mehr in so bedeutendem Maße wie auf jüngeren Stadien.

\section{Entwicklung des Embryos und des Endosperms.}

Irgendwelche Anzeichen von Befruchtung konnte ich an der untersuchten Sciaphila-Art nicht auffinden. Pollenschläuche waren weder im Gewebe des Griffels noch im Inneren der Samenanlage zu beobachten. Die Mikropyle der letzteren bleibt, wie dies auch Poulsen (l. c. pag. 13) für Sciaphila nana Bl. angibt, stets fest geschlossen und ist zudem von der Ansatzstelle des Griffels an der Basis des Fruchtknotens durch den Funiculus getrennt.

Die Eizelle entwickelt sich also vermutlich parthenogenetisch oder apogam. Auf dem Stadium, das in der Textfigur $20 a$ wiedergegeben ist, hat die Eizelle an Größe schon beträchtlich zugenommen. Sie zeigt immer noch geringen Plasmagehalt. Nur am Scheitel, in der Nähe des Zellkernes, bildet das Cytoplasma einen etwas dichteren Belag. Die 
Synergiden sind schon stark in Degeneration begriffen. Es sind von ihnen nur noch die beiden Kerne und ein kleiner Plasmarest sichtbar. In der Nähe der Eizelle liegt der große sekundäre Embryosackkern. Er ist in der Längsrichtung des Embryosackes etwas gestreckt. Anzeichen einer baldigen Teilung sind an ihm noch nicht sichtbar.

Die erste Teilung des Eikerns kam mir nicht zu Gesicht. Dagegen fand ich ein Stadium, wo die Keimzelle zwei Kerne enthielt,
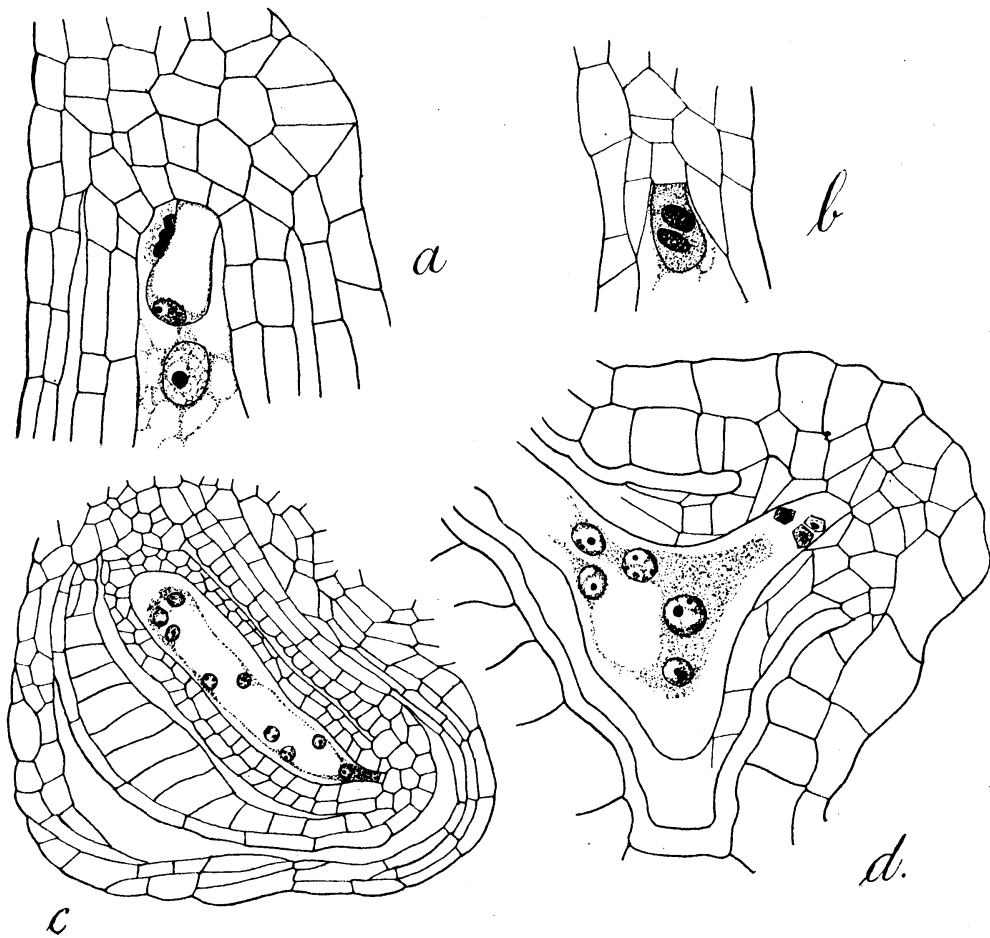

Fig. 20. $a$ Eizelle, daneben die degenerierten Synergiden. Vergr. 410/1. $b$ Keimzelle mit zwei Kernen. Vergr. 410/1. c Embryosack mit neun Endospermkernen. Im äußeren Integument haben sich die Zellen der inneren Schicht schon stark gestreckt. Vergr. 125/1. d Antipodenende des Embryosackes zur Zeit der Endospermbildung. Reste der Antipodenzellen. Vergr. 410/1.

zwischen denen eine Wand noch nicht deutlich wahrnehmbar war. Die beiden Kerne zeigten eine länglichovale Gestalt und lagen quer zur Längsachse der Eizelle (Textfigur 20 b). Weitere Stadien aus der ersten Entwicklung des Embryos begegneten mir nicht. Ich fand ihn immer erst in seiner vollen Ausbildung, rings von Endospermgewebe umgeben, wieder. 
Poulsen gibt in seiner Arbeit über Sciaphila nana Bl. eine Abbildung eines dreizelligen Embryos, der genau am Scheitel des Embryosackes inseriert ist (1. c. Taf. VI, Fig. 23).

Der ausgewachsene Embryo ist keulenförmig. Sein kurzer Stiel wird von zwei Suspensorzellen gebildet. Von seiner Umgebung hebt er sich infolge der starken Färbbarkeit seiner Kerne und durch seine kleinen Zellen, die den Endospermzellen an Größe bedeutend nachstehen, deutlich ab (Taf. IV, Fig. 26). Er ist klein, wenigzellig und ungegliedert. In seiner Form stimmt er mit dem Embryo von Sciaphila Schwakeana ${ }^{1}$ ) überein. Auch für jene Art gibt Johow einen Suspensor an (1. c. pag. 517: „Der Embryo ist wie bei den Burmanniaceen rudimentär und ungegliedert, er besteht aus einer größeren Anzahl von Zellen als bei irgend einer bekannten Art dieser Familie und ist ferner auch durch den Besitz eines kurzen Trägers ausgezeichnet." Der Inhalt der Trägerzellen stirbt auf älteren Stadien ab und wird resorbiert. Sie sind dann oft nicht leicht nachzuweisen, und bei oberflächlicher Betrachtung bekommt man den Eindruck, als liege der Embryo ganz isoliert
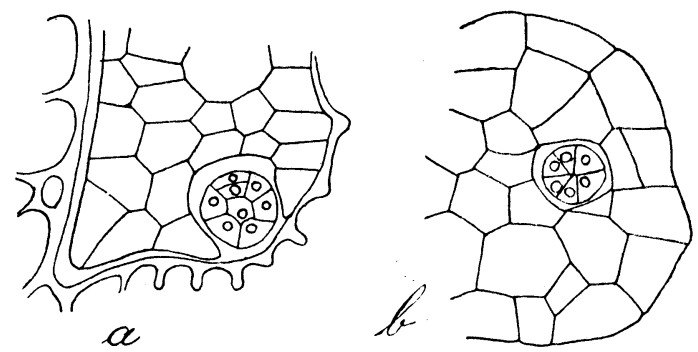

Fig. 21. a Querschnitt durch Embryo und Endosperm, nahe der Insertionsstelle des ersteren. Vergr. 175/1. $b$ Schnitt durch Embryo und Endosperm, näher dem Scheitel des Embryos. Vergr. 175/1. im Inneren des Endo-

sperms. Die scheinbar laterale Insertion des Embryos an der Embryosackwandung ist die Folge einer Gestaltveränderung, die der Embryosack durch das Auswachsen von Zellen des äußeren Integumentes erleidet. Der Embryo selbst erhält durch diese Wachstumsprozesse außerhalb des Embryosackes liegender Gewebe eine exzentrische Lage im Endosperm, wie sie aus der Textfigur $21 a$ u. $b$ ersichtlich ist. Die in unmittelbarer Umgebung des Embryos liegenden Endospermzellen sind bedeutend kleiner als die weiter entfernten. Auch ihre Kerne haben geringere Dimensionen als diejenigen der übrigen Zellen des Endospermgewebes. Sie sind etwa von der Größe der Kerne des Embryos und sind noch zu Teilungen befähigt, wenn sich die Wände der übrigen

1) Johow, F., „Die chlorophyllfreien Humuspflanzen“, Pringsheim's Jahrbücher, Bd. XX, 1889, pag. 517. 
Endospermzellen schon verdickt haben und ihre Kerne in den Ruhezustand getreten sind. Durch diese Teilungen der dem Embryo benachbarten Zellen werden kleine „Füllzellen“ gebildet, denen vielleicht die Funktion zukommt, kleinere Lücken, die zwischen Embryo und Endospermgewebe übrig bleiben, zu schließen. Die Kerne dieser „Füllzellen" zeigen intensives Tinktionsvermögen und sind $\mathrm{zu}$ einer Zeit noch sichtbar, wo diejenigen der eigentlichen Endospermzellen verschwunden sind (Taf. IV, Fig. 26).

Die erste Teilung des sekundären Embryosackkernes konnte ich nicht beobachten. Immerhin ist es sicher, daß sie vor der ersten Teilung des Eikernes erfolgt. In dem um diese Zeit stark in die Länge wachsenden Embryosack bildet sich in normaler Weise ein regelmäßiger Wandbelag mit freien Endospermkernen. Letztere sind größer als die Kerne der umliegenden Gewebe, rund oder länglichrund und enthalten mehrere Kernkörperchen. Teilungen der Endospermkerne konnte ich vielfach beobachten. Sie erfolgen im ganzen Embryosack gleichzeitig. Taf. IV, Fig. 27 zeigt zwei Endospermkerne in Vorbereitung zur Teilung begriffen.

Ob die Weiterentwicklung des Endosperms durch simultane Zellbildung im Wandbeleg und nachfolgende tangentiale Teilungen der so entstandenen Zellen vor sich geht, kann ich nicht sagen. Das Endospermgewebe bildet ein regelmäßiges, großmaschiges Zellennetz. Die Wände sind anfangs dünn, verdicken sich aber mit der Zeit. Namentlich werden die freien (nicht an andere Endospermzellen anstoßenden) Membranen der peripheren Endospermzellen stark ausgebildet, so daß der ganze Endospermkörper auf Quer- oder Längsschnitten von einer dicken Leiste umrahmt erscheint (Tafel IV, Fig. 26). Bei Einwirkung von Chlorzinkjod färben sich diese Endospermwände violett, in $80 \%$ Schwefelsäure quellen sie auf und werden in konz. Schwefelsäure vollkommen gelöst. Sie bestehen also aus einer Zellulose, die wohl später vom Keimling gelöst und aufgezehrt wird. Mit Eosin färben sich diese Endospermwände rot, bei Anwendung von Orange nehmen sie eine intensiv gelbe Tinktion an.

Auch im Inneren der Endospermzellen gehen während des Reifungsprozesses der Samen mancherlei Veränderungen vor sich. Ihr Plasma zeigt zunächst wenige, große Vakuolen, die um den zentralen Kern angeordnet sind. Sie lösen sich später in ein Netz kleinerer Vakuolen auf (Taf. IV, Fig. 28). Das plasmatische Gerüstwerk zwischen den Vakuolen verdichtet sich stellenweise zu kompakten Körnchen, die mit der Zeit zu größeren, intensiv sich färbenden Klumpen zusammen- 
fließen. Die anfangs zackige Kontour dieser Klumpen rundet sich später ab. Sie werden dadurch tropfenförmig (Taf. IV, Fig. 29 und 30). Bei Einwirkung von Salpetersäure nehmen diese Reservestoffkörper deutlich eine gelbe Färbung an, bestehen also wohl aus Eiweißsubstanzen.

Während der Bildung besagter klumpiger Reservestoffkörper degeneriert der Kern der Endospermzellen. Er verliert seine regelmäßig gerundete Form und erscheint an seiner Peripherie in spitze Fortsätze ausgezogen, wodurch er oft eine sternförmige Gestalt erhält und den Eindruck erweckt, als wolle er sich in dem umgebenden Plasma auflösen. Im völlig reifen Endospermgewebe lassen sich keine Kerne mehr nachweisen.

\section{Entwicklung der Samenschale.}

Neben der Ausbildung des Embryos und des Endosperms gehen Wachstumsvorgänge und Gestaltsveränderungen im Bereiche der sie umgebenden Gewebe einher.

Das innere Integument hat keinen Anteil am Aufbau der Samenschale. $\mathrm{Zu}$ einer Zeit, wo im protoplasmatischen Wandbelege erst wenige Endospermkerne auftreten, sind seine Zellen schon zusammengedrückt und in Degeneration begriffen. In der Folge werden sie vom heranwachsenden Endosperm resorbiert. Am reifen Samen ist vom inneren Integument nichts mehr vorhanden. An das Endosperm schließt sich nach aufen direkt das äußere Integument an. Etwas anders scheinen die Verhältnisse bei Sciaphila Schwakeana zu liegen. Nach einer Zeichnung Johow's (I. c. Taf. XXII, Fig. 22), die einen Längsschnitt durch die Frucht der genannten Pflanze gibt, schiebt sich zwischen Endosperm und Integument noch eine weitere Zellage ein. Der genannte Autor sagt davon (l.c. p.517): „Die einfache, zusammengedrückte Zellage, welche den kleinzelligen Körper im Innern umgibt, gehört dem Nuzellus an, wie aus dem Vergleich mit den von Poulsen abgebildeten jüngeren Zuständen unzweifelhaft hervorgeht". Es würde also nach diesen Angaben bei Sciaphila Schrokeana, die den Embryosack umhüllende Nuzellusschicht, auch im reifen Samen persistieren, während für die uns vorliegende Art eine frühzeitige Degeneration derselben nachgewiesen wurde. Johow geht übrigens bei der Deutung der erwähnten Zellschicht von der Annahme aus, daß bei der Gattung Sciaphila nur ein Integument zur Ausbildung komme. Er stützt sich dabei auf die Angabe Poulsen's, daß Sciaphila caudata nur ein Integument besitze. Auf Grund seiner neueren Untersuchungen an Sciaphila nana Bl. erklärt aber der letztgenannte Forscher selbst die 
Frage nach der Zahl der Integumente in der Gattung Sciaphila als der Revision bedürftig (l. c. pag. 14).

Im Gegensatz zum inneren spielt das äußere Integument eine große Rolle bei der Bildung der Samenschale, namentlich ist es die innere der beiden Zellschichten, die sich in hervorragender Weise daran beteiligt. Sie unterscheidet sich schon früh von der äußèren Zellage, in erster Linie durch die Zahl der Zellen, die sie zusammensetzen. Auf eine der langgestreckten Zellen der äußeren Schicht kommen ca. zwei der inneren. Und diese Zellen der inneren Zellage zeigen noch das normale Aussehen und lebenden Inhalt, während diejenigen der äußeren Zellschicht schon abgestorben sind und ihre Wände sich mit der gelblichen, hell lichtbrechenden Substanz bedeckt haben. Die spezifische Ausbildung der Zellen der inneren Schicht setzt ein mit den ersten Teilungen der Endospermkerne innerhalb des Embryosackes. Um diese Zeit beginnen sie sich in radialer Richtung senkrecht zur Längsachse des Embryosackes zu strecken. Diese Streckung geht während der Entwicklung des Endosperms weiter, bis die besagten Zellen das Drei- bis Vierfache ihrer Länge erreicht haben. Im übrigen strecken sich nicht alle Zellen der inneren Schicht gleichmäßig. Am stärksten verlängern sich diejenigen, die auf halber Höhe des Embryosacks liegen; gegen die Pole zu nimmt das Streckungsvermögen ab. Textfigur $22 a$ gibt diese Verhältnisse wieder. Aus jener Zeichnung geht auch hervor,

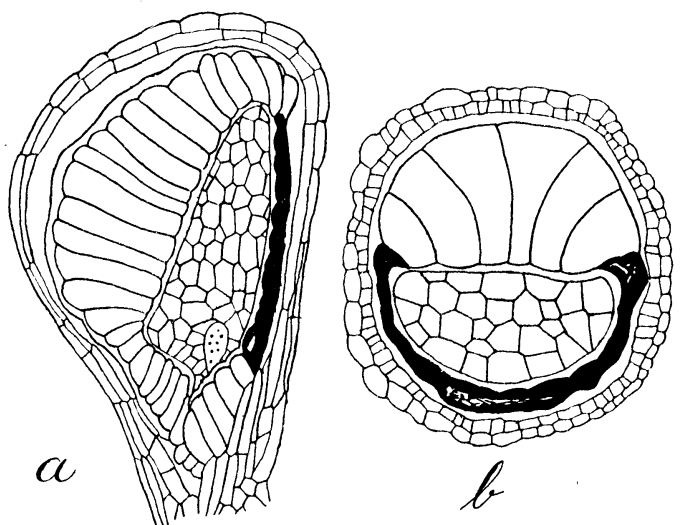

Fig. 22. a Längsschnitt durch Frucht und Samen. Vergr. 50/1. $b$ Querschnitt durch Frucht und Samen. Vergr. $70 / 1$. daß nur auf der einen Seite der Frucht, und zwar auf der gegen den Rand des Fruchtbodens gerichteten, diese Streckungsvorgänge stattfinden. Auf der Funikularseite werden die Zellen des äußeren Integumentes zusammengedrückt und lassen weder ihre Form noch ihr Lumen mehr erkennen. Aus der gleichen Figur ist ersichtlich, daß auch die Form des Embryosackes durch dieses starke Auswachsen der Zellen des äußeren Integumentes eine Modifikation erlitten hat. Das früher breit gerundete Ende ist in 
eine scharfe Spitze ausgezogen worden, wobei der ursprüngliche Scheitel des Embryosackes eine Verschiebung erlitt, so daß der Embryo seitlich zu liegen kommt.

Einen Querschnitt durch die reife Frucht gibt Textfigur $22 b$ wieder. Das Endosperm zeigt in dieser Ansicht ungefähr bohnenförmige Gestalt. Gegen die stark verlängerten Integumentzellen hin ist der Endospermkörper abgeflacht.

Eine ähnliche Entwicklung, des äußeren Integumentes hat auch Johow (1. c. Taf. XXII, Fig. 22) für Sciaphila Schwakeana konstatiert. Zum Unterschied von der hier untersuchten Art haben dort die Zellen beider Schichten des äußeren Integumentes eine radiale Streckung erfahren. Johow möchte die Vergrößerung der gestreckten und später mit Luft erfüllten Integumentzellen mit der Verbreitung der Samen in Zusammenhang bringen.

Gegen das Endosperm hin bilden alle an dasselbe angrenzenden Integumentzellen eine dicke Wand aus, die sich durch Farblosigkeit und starkes Lichtbrechungsvermögen von den übrigen Membranpartien, die einen braunschwarzen Farbenton zeigen, deutlich abhebt. In konzentrierter Schwefelsäure ist diese verdickte Membran unlöslich. Mit Sudan III nimmt sie eine Orangefärbung an, sie ist also kutinisiert.

Wie wir früher gesehen haben, umgab das Fruchtblatt die Samenanlage als eine drei bis vier Zellagen dicke Hülle, in deren aufsteigendem Aste Poulsen bei Sciaphila nana Bl. (1. c. Taf. VI, Fig. 1) einen schwachen Tracheidenstrang nachweisen konnte. Solche leitende Elemente werden bei der hier untersuchten Art im Fruchtblatt nicht mehr ausgebildet, doch fand ich auch hier im aufsteigenden Teile des Carpells, und nur in ihm, in den Zellen Stärkekörner, woraus man wohl schließen darf, daß auch bei vorliegender Art die Zuleitung der Nährstoffe zum Griffelgewebe durch den aufsteigenden Ast besorgt wird, obschon auch der absteigende sekundär mit dem Fruchtboden verwächst.

An der reifen Frucht ist die Wandung am gerundeten Scheitel zwei-, an der Basis dreischichtig. In der innersten Schicht zeigen die Wände Verdickungen, die an diejenigen gewisser Gefäße erinnern, und nehmen mit Phloroglucin und Salzsäure eine schwach rötliche, mit schwefelsaurem Anilin eine gelbliche Färbung an, sind also offenbar verholzt.

Die Frucht ist gedrungen-keulenförmig. Sie ist an ihrer Ansatzstelle am Fruchtboden am schmalsten und verbreitert sich allmählich gegen das distale, abgerundete Ende zu. Nahe der Basis sieht man ihr oft noch die verdorrten Griffelreste ansitzen. 
Die Verbreitung der Samen soll nach Beccari (l. c. pag. 329) durch Regenwürmer resp. Vögel, denen diese Tiere zur Beute werden, erfolgen. Eine Verfrachtung durch den Wind, wie sie Johow (l. c. pag. 517) auf Grund des Baues der Samenschale annehmen möchte, sei nach den Standorten der Pflanzen auf windgeschütztem Waldboden nicht zu erwarten. Die gleiche Verbreitungsweise schreibt Beccari (l. c. pag. 315) auch anderen Saprophyten, die unter ähnlichen Bedingungen wachsen, so z. B. auch der vorher besprochenen Gattung Epirrhizanthes, zu.

\section{Zusammenfassung der Resultate.}

a) Epirrhizanthes elongata.

1. In der zwitterigen Blüte entwickeln sich die Glieder in akropetaler Reihenfolge. In den Antheren werden die Pollenurmutterzellen nach Abgliederung einer subepidermalen Zelle direkt zu den Pollenmutterzellen Die Zahl der letzteren beträgt gewöhnlich drei bis vier. Sie liefern durch simultane Zellbildung die Pollentetraden.

Auf den ersten postsynaptischen Stadien ist die chromatische Substanz in körnigen Gruppen über den ganzen Zellraum verteilt, die jedenfalls den späteren Chromosomen identisch sind. Ihre Zahl beträgt wahrscheinlich 24. Während der Kernteilungen im Innern der Pollenmutterzellen tritt an ihrer Peripherie eine eigentümliche Verdichtung des Protoplasmas auf.

2. Die in der subepidermalen Zellschicht des Nuzellus auftretende Archesporzelle wird nach Abgliederung einer Tapetenzelle zur Embryosackmutterzelle. Von den vier Tetradenzellen entwickelt sich die unterste in normaler Weise zum Embryosack. Die Polkerne verschmelzen vor dem Eindringen des Pollenschlauches zum sekundären Embryosackkern. Die Antipodenzellen degenerieren früh und sind an der $\mathrm{Zu}$ leitung des Nährstoffstromes nicht beteiligt. Die Mikropyle wird allein vom inneren Integument gebildet.

3. Die Antheren öffnen sich durch einen introrsen Längsriß, durch den die schon innerhalb der Pollensäcke keimenden Pollenkörner die Pollenschläuche zur Narbe entsenden. Es findet somit Autogamie statt. Die Teilung des generativen Kernes findet erst innerhalb des Pollenschlauches statt. Der letztere wächst durch ein Griffelgewebe interzellulär der Samenanlage zu, in die er durch die Mikropyle eindringt. Für die Wahrscheinlichkeit einer Befruchtung spricht das regelmäßige 
Eindringen des Pollenschlauches in den Embryosack, das Auftreten von zwei größeren und einem kleineren Kernkörperchen in den Teilungsprodukten des sekundären Embryosackkerns, ebenso das Auftreten eines zweiten Kernkörperchens im Kern der Eizelle.

4. Der Embryo entwickelt sich in normaler Weise. Er zeigt im ausgewachsenen Zustande zwei deutliche Cotyledonen, zwischen denen der schwach gewölbte Vegetationskegel sichtbar ist. $\mathrm{Er}$ ist an der Wand des Embryosackes mittels eines zweizelligen Suspensors befestigt.

5. Die erste Teilung des sekundären Embryosackkernes findet statt vor der Zweiteilung der Eizelle. Die Endospermbildung erfolgt durch freie Kernteilung und nachfolgende simultane Zellbildung. Das Endosperm bildet ein großmaschiges Gewebe, das zum größten Teil vom heranwachsenden Embryo resorbiert wird. Es enthält als Reservestoff Proteinkörner mit Eisweißkrystalloiden und Globoiden.

6. Das Nuzellusgewebe wird während der Samenentwicklung bis auf geringe Reste, das innere Integument vollständig resorbiert. Das äußere Integument ist an der Bildung. der Samenschale in hervorragender Weise beteiligt. Es liefert das „Tapetum." In der Chalazaregion zeigt das „Tapetum“ eine Durchtrittsstelle für den Nährstoffstrom, die nach Sistierung des letzteren verstopft wird.

\section{b) Sciaphila spec.}

1. In den traubigen Blütenständen wird die Spitze von wenigen (4-5) männlichen, die mittlere Partie und die Basis von den weiblichen Blüten eingenommen.

2. An den anfangs kegelförmigen Anlagen der männlichen Blüten entwickeln sich zunächst das sechszählige Perianth, dann in der Dreizahl die Staubblätter, welche an der Basis einen zahnförmigen Gewebehöcker zeigen, der vielleicht als letzter Rest eines Pistillodiums zu deuten ist. Aus dem vielzelligen, sporogenen Komplexe entwickeln sich durch succedane Teilung der Mutterzellen die Pollenkörner. Die Pollenbildung verläuft somit im Rahmen der Monokotylen. Die kleinen, runden Pollenkörner weisen eine dicke Exine auf, Keimporen sind nicht vorhanden. Das Perianth bleibt auch nach der Öffnung der Antheren, die durch einen extrorsen Längsriß erfolgt, geschlossen.

3. Auf dem anfangs flachen, scheibenförmigen Fruchtboden entstehen die Carpelle in akropetaler Reihenfolge. Die wachsende Spitze des Fruchtblattes überwölbt den kegelförmigen Nuzellus, sie verbreitert sich dabei fußförmig. Die Spitze des Fußes wächst zum fadenförmigen Griffel aus, der kein Leitungsgewebe für Pollenschläuche ausbildet. 
4. Die subepidermal im Nuzellus entstehende Archesporzelle wird direkt zur Embryosackmutterzelle. Während ihrer Entwicklung dreht sich die anfangs orthotrope Samenanlage innerhalb des Fruchtknotens und geht in anatrope Stellung über. Von den vier Tetradenzellen wird die unterste zum Embryosack. Dieser zeigt eine keulenförmige Gestalt. Der Eiapparat liegt am breiteren Ende. Die Antipoden sind klein und degenerieren frühzeitig.

5. Anzeichen einer stattfindenden Befruchtung ließen sich nicht auffinden. Pollenschläuche fanden sich weder im Griffelgewebe noch in der Samenanlage. Die Eizelle entwickelt sich vermutlich parthenogenetisch. Der ausgewachsene Embryo ist keulenförmig, aus wenigen, kleinen Zellen bestehend, ungegliedert und durch einen zweizelligen Suspensor an der Wand des Embryosackes befestigt.

Die Teilung des sekundären Embryosackkernes erfolgt vor der ersten Teilung der Eizelle. Die Endospermbildung geschieht durch freie Kernteilung mit nachfolgender simultaner Zellbildung, Im reifen Endosperm sind die Zellwände stark verdickt und bestehen aus Zellulose.

6. Die den Embryosack umschließende, nur eine Zellage dicke Nuzellusschicht wird frühzeitig zerdrückt und resorbiert; das gleiche Schicksal erleidet später das innere Integument. Das äußere Integument persistiert und liefert die Samenschale.

\section{Literaturverzeichnis.}

1) Beccari, O., „Malesia“. Vol. III. Firenze-Roma 1886-1890.

2) Engler, A., „Syllabus der Pflanzenfamilien“. Berlin 1907.

3) Engler u. Prantl, „Die natürlichen Pflanzenfamilien“. II. Teil, 1. Abt., Leipzig 1889.

4) Ders., „Die natürlichen Pflanzenfamilien“. III. Teil, 4. Abt., Leipzig 1897.

5) Hemsley, B. W., „Two new Triuridaceae with some Remarks on the genus Sciaphila Bl.“. Ann. of Bot., 1907, Vol. XXI.

6) Johow, F., „Die chlorophyllfreien Humuspflanzen“. Pringsheim's Jahrbücher, 1889, Bd. XX.

7) Penzig, 0., „Beiträge zur Kenntnis der Gattung Epirrhizanthes Bl.“. Ann. du jard. bot. de Buitenzorg, 1901, Vol. XVII, Sér. 2, Vol. II.

8) Poulsen, V. A., „Triuris major spec. nov.“. Bot. Tidsskr., 1890, Bd. XVII.

9) Ders., „Sciaphila nana Bl.“. Meddel. fra den naturh. Foren i. Kbhvn. 1906.

10) Schmid, E., „Beiträge zur Entwicklungsgeschichte der Scrophulariaceen“ Inaug.-Diss. Zürich, Labor. f. allg. Bot. 1906. 


\section{Erklärung der Tafel IV.}

Fig. 1. Epirrhizanthes cylindrica. Pollenmutterzelle. Stadium des regelmäßigen Kernnetzes. Vergr. 1080/1.

Fig. 2. Epirrhizanthes cylindrica. Pollenmutterzellen. Synapsisstadium. Vergr. 620/1.

Fig. 3. Epirrhizanthes elongata. Pollenmutterzellen mit peripherer Plasmaverdichtung. Chromatingruppen. Vergr. 1080/1.

Fig. 4. Epirrhizanthes elongata. Pollenmutterzelle. Dispiremstadium. Periphere Plasmaverdichtung. 1080/1.

Fig. 5. Epirrhizanthes elongata. Pollenmutterzelle nach der ersten Teilung des Kernes. In der Nähe der Tochterkerne haben sich aufs neue Zonen verdichteten Plasmas gebildet. Vergr. 1080/1.

Fig. 6. Epirrhizanthes elongata. Pollenmutterzelle. Stadium der Tetradenbildung.

Das Plasma noch nicht in 4 Portionen zerfallen. Vergr. 620/1.

Fig. 7. Epirrhizanthes elongata. Pollentetrade. Vergr. 620/1.

Fig. 8. Epirrhizanthes elongata. Pollenkorn. Erste Teilung des Kernes. Vergr. $620 / 1$.

Fig. 9. Epirrhizanthes elongata. Pollenkorn. Generative und vegetative Zelle. Vergr. 620/1.

Fig. 10. Epirrhizanthes elongata. Achtkerniger Embryosack. Vergr. 620/1.

Fig. 11. Epirrhizanthes elongata. Eizelle, in ihrer Nähe die aneinander gelagerten und an der Berührungsstelle sich abplattenden Polkerne. Vergr. 620/1.

Fig. 12. Epirrhizanthes elongata. Länglich-keulenförmig gestaltete Polkerne. Vergr. $620 / 1$.

Fig. 13. Epirrhizanthes elongata. Keimendes Pollenkorn. Vergr. 430/1.

Fig. 14. Epirrhizanthes elongata. Pollenschlauchspitze mit den beiden Spermakernen. Vergr. 1080/1.

Fig. 15. Epirrhizanthes elongata. Narbenpapillen mit Sekretkappen von schwammigvakuoliger Struktur. Vergr. 190/1.

Fig. 16. Epirrhizanthes elongata. Endospermkern mit zwei größeren und einem kleineren Nukleolus. Vergr. 620/1.

Fig. 17. Epirrhizanthes elongata. „Tapetenzellen“ zu Beginn der Längsstreckung. Vergr. 620/1.

Fig. 18. Epirrhizanthes elongata. „Tapetenzellen“ auf ihre definitive Länge gestreckt; Kerne an die äußere Querwand gerückt. Vergr. 620/1.

Fig. 19. Epirrhizanthes elongata. „Tapetenzellen“, an den Längswänden stark verdickt. Vergr. 620/1.

Fig. 20. Epirrhizanthes elongata. „Tapetenzellen“ in ihrer völligen Ausbildung, Zellraum auf eine schmale Spalte reduziert. Vergr. 620/1.

Fig. 21. Epirrhizanthes elongata. Zuleitungsgewebe am Chalazaende der Samenanlage. Darüber am Grunde des Embryosackes einzelne Endospermzellen. Vergr. 360/1.

Fig. 22. Sciaphila spec. Pollenkorn kurz nach der ersten Kernteilung. Vergr. 1080/1.

Fig. 23. Sciaphila spec. Pollenkorn mit (dunklem) generativem und vegetativem Kerne. Vergr. 1080/1.

Fig. 24. Sciaphila spec. Pollenkorn mit dem vegetativen und den beiden generativen Kernen. Vergr. 1080/1. 
446 Hans Wirz, Beiträge zur Entwicklungsgeschichte von Sciaphila spec. usw.

Fig. 25. Sciaphila spec. Archesporzelle kurz vor der Synapsis. Vergr. 620/1.

Fig. 26. Sciaphila spec. Embryo mit Suspensor und Endospermgewebe. Vergr. 620/1. Fig. 27. Sciaphila spec. Freie Endospermkerne in Vorbereitung zur Teilung begriffen. Vergr. 1080/1.

Fig. 28. Sciaphila spec. Junge Endospermzelle mit zahlreichen Vakuolen. Vergr. $620 / 1$.

Fig. 29. Sciaphila spec. Etwas ältere Endospermzelle. Inhalt teilweise zu kompakten Klumpen verdichtet. Vergr. 620/1.

Fig. 30. Sciaphila spec. Die zackigen Klumpen haben sich an der Peripherie abgerundet und tropfenförmige Gestalt angenommen. Vergr. 620/1. 